UNIVERSIDAD NACIONAL DE LA PLATA

FACULTAD DE CIENCIAS MÉDICAS
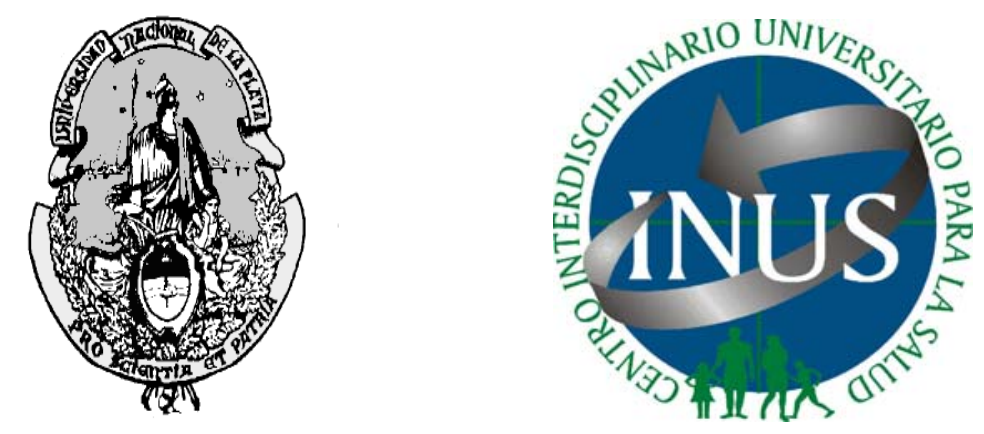

\title{
ESTUDIO EPIDEMIOLÓGICO DE OBESIDAD Y SOBREPESO EN NIÑOS DE AMBOS SEXOS DE 6 a 10 AÑOS DEL PARTIDO DE OLAVARRÍA, PROVINCIA DE BUENOS AIRES, ARGENTINA
}

\author{
TESIS \\ MAESTRÍA EN SALUD PÚBLICA \\ Orientación: Establecimientos y Servicios de Atención Médica
}

Médica NORA ELISABET ZEBERIO Director: DR HORACIO F. GONZÁLEZ

La Plata, Diciembre 2010 


\section{A mis hijos}

Sebastián, Federico y Mariano 


\section{ÍNDICE}

Pág.

1. INTRODUCCIÓN........................................................ 4

2. FUNDAMENTACIÓN …...............................................

3. MARCO CONCEPTUAL. LA OBESIDAD Y LA SALUD ............... 7

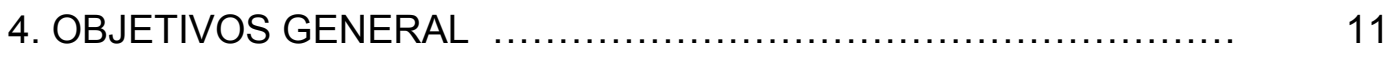

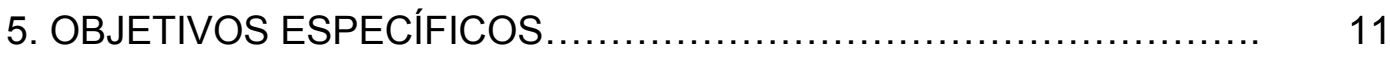

6. MATERIAL Y MÉTODOS

6.1 Tipo de estudio

6.2 Universo de estudio

6.3 Variables de estudio

7. ANÁLISIS DE DATOS....................................................... 20

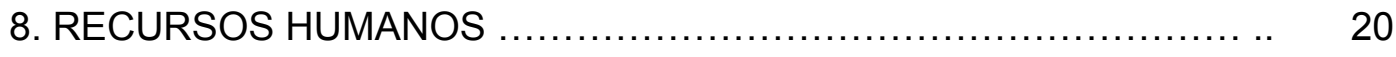

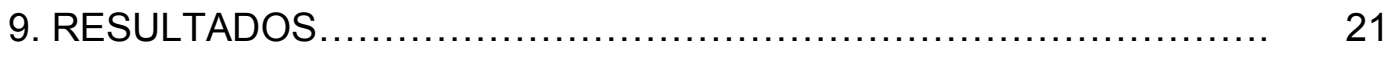

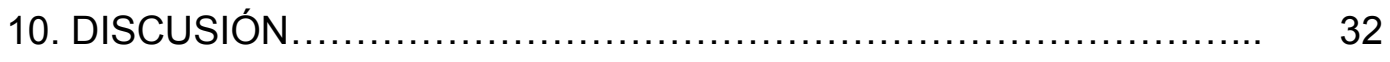

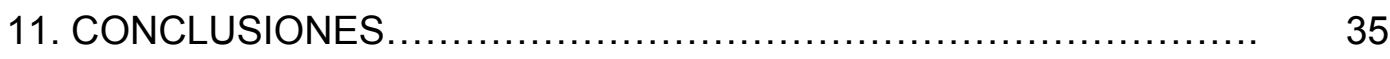

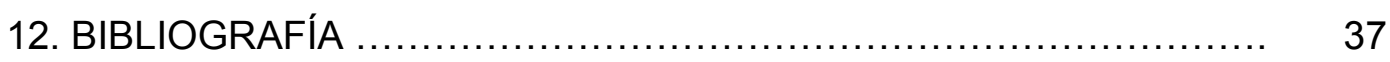

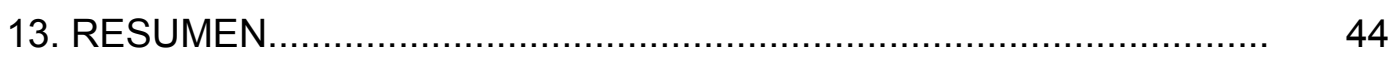

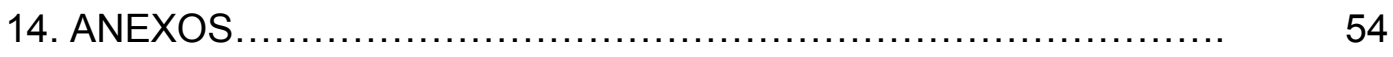




\section{INTRODUCCIÓN}

La obesidad infantil constituye un serio problema de la salud pública en nuestro país, siendo uno de los problemas más comunes en niños y adolescentes, habiéndose documentado aumentos en su prevalencia en las últimas décadas ${ }^{(1)}$.

Lo mismo ocurre en América Latina y el Caribe donde se notificó un aumento notable de la prevalencia de exceso de peso. Las tasas más altas se observan en EEUU y Europa, pero la tendencia de incremento es bastante generalizada en países tan diversos como Brasil y China ${ }^{(2)}$.

En estudios recientes se analizaron las tendencias del sobrepeso en niños y adolescentes de 6 a 18 años, en 4 países, y en un período que va de 6 a 20 años, analizados según el índice de masa corporal (IMC) para la edad recomendados por la INTERNATIONAL OBESITY TASK FORCE ${ }^{(2)(3)}$.

Las tendencias halladas fueron en Brasil de $4.1 \%$ a $13.9 \%$, en China de $6.4 \%$ a $7.7 \%$, en EEUU de $15.4 \%$ a $25.6 \%$, y en Rusia, único país en el que bajó la prevalencia, de $15.6 \%$ a $9 \%{ }^{(2)}$.

La tendencia al aumento de la obesidad en los niños podría ser el resultado de cambios culturales y ambientales relacionados con la inactividad física en las sociedades modernas considerando que los riesgos están más relacionados con el medio ambiente, aspectos culturales o circunstancias individuales que herencia genética ${ }^{(4)}$.

La combinación de peso insuficiente en niños y sobrepeso en adultos, con frecuencia coexiste en una misma familia, es un fenómeno relativamente nuevo hallado en países en vías de desarrollo que sufren la transición de nutrición, cambio de dietas, la distinta disponibilidad de alimentos y los cambios en el modo de vida ${ }^{(5)}$.

Tradicionalmente la obesidad ha sido unida con la abundancia y era previsible que aumentara en los países que mejoraron su estado económico y su PBI. Pero no ha sido así. La relación entre el PBI y sobrepeso es compleja (5). 
En los países pobres la ingesta calórica de la población de más bajos recursos podría ser limitado por la escasez de alimentos y la alta demanda de gasto energético por el trabajo manual, y las actividades de supervivencia diaria hacen difícil que la gente obtenga un balance energético positivo para ganar peso. Sin embargo la disponibilidad de productos de alimentación baratos (con mucha energía calórica) incluyendo los que se venden en las calles y los comercios de comidas rápidas facilitan el consumo de energía favoreciendo la obesidad ${ }^{(5)}$.

El acceso a la televisión, y a juegos de pantalla electrónica favorece el sedentarismo como otro dato negativo en la pérdida de peso ${ }^{(6)}$.

En los estratos sociales medios y altos de la población estas influencias son compensadas con mejor acceso a educación sobre salud y nutrición, el ingreso suficiente para comprar productos dietéticos y más sanos (generalmente mas caros), la mayor cantidad de tiempo disponible para la actividad física y el mejor acceso a la asistencia médica ha ayudado a dirigir mejor los problemas de sobrepeso en esta franja poblacional ${ }^{(5)}$.

Muchas complicaciones metabólicas y cardiovasculares, y algunas formas de cáncer asociados con obesidad en el adulto tienen sus comienzos en la infancia. La comprensión de la relaciones entre la obesidad del niño y el adolescente y la del adulto es un elemento muy valioso para tratar de implementar medidas adecuadas para su tratamiento y prevención $(4,7,8,9,10)$.

La prevalencia de obesidad en los estudios realizados en Argentina en la última década oscila entre el $4.1 \%$ y $11 \%{ }^{(10)}$, (año 2000 ).

En la Encuesta Nacional de Nutrición y Salud (ENNyS) realizada por el Ministerio de Salud de la Nación, se hace referencia a que la media nacional de prevalencia de obesidad fue 4.4\% (IC 95\%, 3,8-5.1\%), (año 2000) en los niños y niñas entre 6 y 72 meses según curvas SAP. Pero evaluados según curvas de OMS, presentó obesidad el 10.4\% (IC 95\%, 9,3-11.5\%) de los niños y niñas entre 6 y 60 meses ${ }^{(11)}$. La prevalencia de sobrepeso en el país es de $31,5 \%$ (IC $95 \%, 30.2-32.9)$, proporción que no varía con la edad ${ }^{(11)}$.

La información de prevalencia de sobrepeso y obesidad de nuestro país que existen son de diversos estudios con objetivos, metodologías y criterios de diagnósticos distintos. Sin embargo estos datos de los últimos 20 años sirven para expresar la transición epidemiológica que vive nuestro país y la región 
respecto de la convivencia de prevalencia de desnutrición (decreciente) y sobrepeso y obesidad (creciente) ${ }^{(12,13,14,15,16,17)}$. La mayoría de los estudios fueron realizados en niños menores de 6 años y/o mayores de 10 años y sólo la ENNyS fue representativa de la población general.

El Consenso de la Sociedad Argentina de Pediatría sobre factores de riesgo de enfermedad cardiovascular en Pediatría ${ }^{(10)}$ plantea la prevalencia de la obesidad en niños en diferentes grupos etáreos. Sin embargo muestra la escasa información en niños de 6 a 10 años.

El único estudio realizado en escolares de la Ciudad de Buenos Aires de 6 a 13 años, no representativo de la población general, sin evaluar la situación socioeconómica muestra una prevalencia de sobrepeso del $29 \%$ y $12,3 \%$ de obesidad ${ }^{(17)}$.

La probabilidad de la Obesidad Infantil (OI) de persistir en la adultez es del $20 \%$ a los 4 años de edad y $80 \%$ en la adolescencia ${ }^{(18)}$.

Debido al aumento de la prevalencia de la Obesidad Infantil es necesario hacer un diagnóstico oportuno y aportar todo el conocimiento de las consecuencias en función de futuras intervenciones preventivas tempranas.

Los tratamientos suelen controlar la Ol a corto plazo, pero debido a la dificultad de controlar el peso a largo plazo, la prevención sigue siendo la mejor herramienta terapéutica ${ }^{(18)}$. 


\section{FUNDAMENTACIÓN}

La Encuesta Nacional de Nutrición y Salud, realizada en el 2007 por el Ministerio de Salud de la Nación, no toma la franja etárea de la población objetivo del presente protocolo ${ }^{(11)}$.

Los hábitos de vida saludable se incorporan a la educación primaria escolar ${ }^{(19,20)}$. El niño es participe y receptor de la educación.

El creciente número de consultas en edad pediátrica de obesidad, sobrepeso e hipertensión arterial en la práctica diaria crea la necesidad de contar con un diagnóstico preciso de las cifras de obesidad infantil, sobrepeso y su relación con la hipertensión arterial para realizar una adecuada intervención en políticas de salud nacionales. El desarrollo de políticas a nivel municipal necesita de información precisa de la problemática local para ser abordada.

Por eso se considera que la muestra del municipio debe representar a toda la población incluida en todos los estratos sociales. Uno de los sesgos de muchos de los estudios realizados en nuestro país es la focalización en algún estrato social (alto o bajo).

La relación entre la presencia de sobrepeso y obesidad y su impacto sobre el sistema cardiovascular fue establecida por métodos sencillos y no invasivos: indicadores antropométricos de estado nutricional y tensión arterial.

\section{MARCO CONCEPTUAL. LA OBESIDAD Y LA SALUD}

En Argentina, como en la mayoría de los países del mundo occidental, padecemos una grave epidemia de enfermedades crónicas no transmisibles (ECNT), particularmente enfermedades cardiovasculares $(E C V)^{(10)}$. Éstas encabezan las causas de muerte desde comienzos de la década del 70 . Ciertos patrones de comportamiento y hábitos contribuyen de manera importante al desarrollo de este grupo de enfermedades.

La obesidad es una enfermedad caracterizada por el aumento de la grasa corporal, definida como tal por la OMS en 1997. En la mayoría de los casos se acompaña de aumento de peso, cuya magnitud y distribución condicionan la salud del individuo. El sobrepeso es el exceso de peso con riesgo de obesidad. 
Evaluar el exceso de peso de una persona presupone dos aspectos: la posibilidad de medirlo en forma precisa y la necesidad de contar con valores normales según edad y sexo, ante los cuales comparar la medición.

La evaluación de la grasa corporal no puede medirse en los seres humanos directamente, por ello existen varias medidas indirectas para usar en niños y adolescentes. En la práctica clínica se promueven los indicadores Antropométricos: Peso según la talla (P/T); Pliegues cutáneos; Circunferencia de la cintura para valorar la distribución de la grasa, Índice de Masa Corporal.

También se desarrollaron otros métodos específicos para medir con más precisión la masa grasa, como la impedancia bioeléctrica, absorción dual de rayos $X$ (DEXA), pero de elevado costo y baja accesibilidad para estudios poblacionales.

El índice mas aceptado actualmente para evaluar la obesidad infantil es el IMC: Índice de Masa Corporal.

El índice de Masa Corporal o índice de Quetelet es una expresión del peso referido a la talla y se calcula dividiendo el peso corporal expresado en kilogramos por la talla elevada al cuadrado expresada en metros ${ }^{(21)}$.

En niños el IMC guarda muy buena relación con la grasa corporal medida por pliegues cutáneos ${ }^{(22)}$.

La OMS recomienda las tablas de referencias internacionales del National Center for Health Statistics (NCHS) y CDC para IMC, con las revisiones realizadas en el 2000 considerando como punto de corte los percentilos 85 para sobrepeso y 95 para obesidad ${ }^{(23)}$.

La circunferencia de la cintura es buen predictor de la distribución central de la grasa. Se asocia a mayor riesgo de padecer el síndrome metabólico ${ }^{(17,22,}$ 24, 25).

De acuerdo a McCarthly se define obesidad central cuando la circunferencia de la cintura es igual o mayor al percentilo $90^{(24)}$.

La hipertensión arterial se define como los niveles de TA sistólica (TAS) o diastólica (TAD) iguales o superiores al percentil 95 (P95) para una determinada edad, sexo y percentil de talla ${ }^{(26,27)}$.

En los últimos veinte años ha surgido evidencia convincente que vincula factores de riesgo definidos en los adultos obesidad, sedentarismo, tabaquismo, hipertensión e hipercolesterolemia con procesos ateroescleróticos. 
En su patogenia se identifican factores hemodinámicos y trombóticos asociados al metabolismo de lípidos e hidratos de carbono y a las características propias de la pared arterial, así como otros vinculados con el estilo de vida .La progresión de la ECV y la gravedad que alcanza se relacionan con la presencia de estos factores de riesgo y con su persistencia a lo largo del tiempo $(10,18,22)$.

Sobre la base de datos de anatomía patológica se conoce que el proceso ateroesclerótico se inicia en la infancia y el grado de extensión de las lesiones en niños y adultos jóvenes se correlaciona con la presencia de los mismos factores de riesgo identificados en adultos ${ }^{(22)}$.

La enfermedad cardiovascular aterosclerótica es una de las primeras causas de muerte en el adulto y se asocia fuertemente con el síndrome metabólico y la diabetes del tipo $2^{(10)}$.

La obesidad desempeña un papel central en el síndrome metabólico que se caracteriza por la asociación de hiperglucemia insulinorresistente, hipertensión arterial, dislipemia, diabetes tipo 2 y aumento de riesgo de enfermedad aterosclerótica cardiovascular.

La Obesidad Infantil fue asociado con dislipidemias, hipertensión arterial, Hiperinsulinismo, insulinorresistencia, intolerencia a la glucosa, DBT 2, ovario poliquístico, depresión, disminución de la autoestima, stress psicológico y estigmatización social, asma, apneas obstructivas del sueños, Síndrome de Pickwick, problemas ortopédicos (genu varun, epifisiolisis de la cabeza femoral), esteatohepatitis no alcohólica ${ }^{(27-33)}$.

El incremento de la obesidad en pediatría ha ocasionado que la hipertensión se presente con mayor frecuencia en esta etapa de la vida, afectando 1 a $3 \%$ de los niños y hasta $10 \%$ en la adolescencia ${ }^{(10,26)}$.

La asociación de la obesidad con el síndrome insulina resistente y el riesgo cardiovascular no se debe solamente al grado de obesidad, sino que estaría vinculado directamente al patrón de distribución de la grasa. En los niños, al igual que en los adultos, se ha demostrado que aquellos con mayor adiposidad central (grasa abdominal) son mas propensos a desarrollar este síndrome. El aumento de la circunferencia de la cintura en niños se asocia con hipertensión sistólica y diastólica, hipercolesterolemia, bajo colesterol HDL, hipertriglicéridos e insulinorresistencia ${ }^{(22,26)}$. 
La urbanización y los nuevos estilos de compra de alimentos han producido notables cambios en las pautas tradicionales de alimentación.

Los cambios alimentarios se refieren principalmente a la dependencia de productos manufacturados, algunos precocidos o de rápida preparación, generalmente ricos en sal (cloruro y glutamato de sodio), en grasas saturadas, ácidos trans y en carbohidratos simple y o azúcar refinado $\left.{ }^{(19,20}\right)$.

Por la proporción de mujeres que trabajan fuera del hogar el tiempo que se le dedica a la cocina es cada vez menor.

Todo esto deterioró la costumbre de reunir a la familia para consumir alimentos preparados en el hogar, tradición que viene desde los inicios de la humanidad con las rondas alrededor de los fogones mientras cocinaban animales y comidas.

La reunión familiar para la comida diaria ha sido cambiada en la mayoría de los hogares por la TV y más aún el advenimiento de los nuevos electrodomésticos como el microondas que ha llevado a la preparación o cocción rápida de alimentos en cualquier hora del día contribuyendo a una mala alimentación ${ }^{(4,5)}$.

De acuerdos a estudios realizados el ambiente socioeconómico tiene una gran importancia en el desarrollo de la Obesidad Infantil. Los pobres no comen lo que quieren, ni lo que saben que deben comer, sino lo que pueden. Los pobres están desnutridos porque no tienen lo suficiente para alimentarse y son obesos por que se alimentan mal, con un desequilibrio energético importante. Los alimentos que tienen a su alcance son productos industrializados, de producción masiva, indiferenciada y barata. En el área metropolitana de Buenos Aires, principal conglomerado de la Argentina, los precios de las frutas y verduras, carnes magras y los lácteos tienden a aumentar más que los precios promedios de inflación. Ante esta situación los pobres seleccionan alimentos ricos en carbohidratos, grasas y azúcares aunque les impide llegar a una nutrición adecuada, satisfacen su apetito. Por otra parte la industria de la alimentación favorece ese comportamiento al segmentar la oferta y comercializar productos masivos, de baja calidad y mayor contenido de azúcares y grasas, que son dirigidos a los sectores con menor poder adquisitivo ${ }^{(34,35,36)}$. 
La distribución del ingreso en la sociedad argentina durante los últimos años ha mostrado que todos los grupos de la población, a excepción de los más ricos, han sufrido una pérdida que de uno u otro modo va a influenciar en la salud de las futuras generaciones ${ }^{(35,36)}$.

La actividad física y las horas de juego al aire libre favorecen el gasto energético beneficiando el desarrollo de la motricidad gruesa, la inserción social, las experiencias cognitivas, la exploración y el contacto con el medio ambiente.

La actividad física es uno de los componentes principales del gasto energético (representa el $15 \%$ del total) ${ }^{(19,20)}$.

Las condiciones actuales de vida en las grandes ciudades, con espacios reducidos, falta de tiempo de los padres, inseguridad en la vía pública, determinan una importante reducción en este componente del gasto predisponiendo a la obesidad. El 25\% de los niños de EE.UU. de 8 a 16 años

miran más de 4 hs. de TV diarias ${ }^{(6,37)}$. La clase social, los modos de vida o los comportamientos de las personas afectan estrechamente la salud y el bienestar de la población ${ }^{(34,36)}$.

\section{OBJETIVO GENERAL}

Realizar un estudio epidemiológico sobre Obesidad Infantil y Sobrepeso en niños de ambos sexos de 6 a 10 años que concurren a establecimientos escolares del Partido de Olavarría, provincia de Buenos Aires, Argentina.

Contribuir a la definición de políticas de salud a nivel Municipal.

\section{OBJETIVOS ESPECÍFICOS}

- Determinar la prevalencia de Obesidad y sobrepeso infantil en una muestra representativa del partido de Olavarria.

- Establecer la relación entre obesidad, sexo y edad.

- Establecer la asociación entre la tensión arterial y el estado nutricional.

- Establecer la correlación de la medida del perímetro abdominal con el estado nutricional. 


\section{MATERIAL Y MÉTODO}

\subsection{TIPO DE ESTUDIO: EPIDEMIOLÓGICO DESCRIPTIVO Y ANALÍTICO DE}

CORTE TRANSVERSAL

Lugar donde se desarrolló el estudio: El Partido de Olavarría se encuentra ubicado en el centro de la Provincia de Buenos Aires, Argentina, (37 S., $60^{\circ}$ O.), su relieve corresponde a la llanura pampeana con serranías al centro-este del partido. Su superficie es de $7.715 \mathrm{Km}^{2}$ y viven en ella 103.000 habitantes.

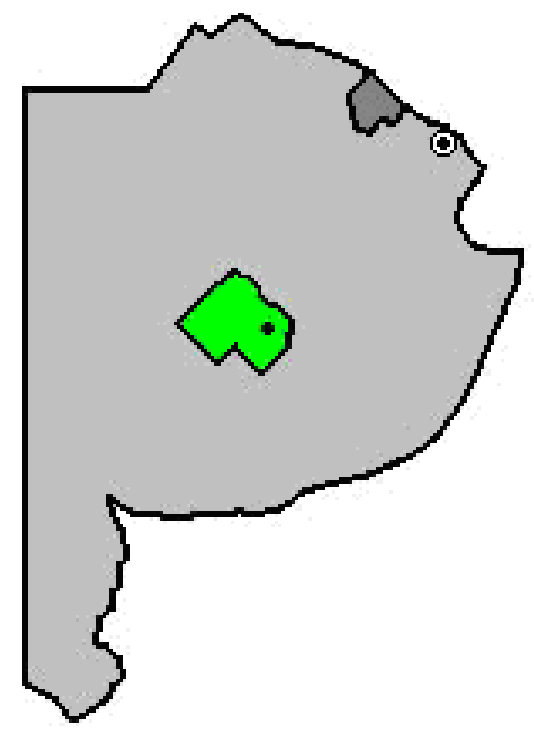

Gráfico 1: Provincia de Buenos Aires, ubicación del partido de Olavarría

Su orografía esta compuesta por cerros, sierras y elevaciones menores, pertenecientes al Sistema de Tandilia, que se prolonga desde este Partido hasta la Sierra de los Padres, con una extensión aproximada de $330 \mathrm{Km}$. Las sierras no sobrepasan los $500 \mathrm{~m}$ sobre el nivel del mar.

La hidrografía está representada por lagunas y arroyos, algunos de cursos permanentes y otros temporarios.

El arroyo más importante para la población es el Tapalqué, que nace en los Manantiales de Querandíes y cruza la ciudad de sur a norte. La laguna más visitada, Blanca Grande, está ubicada en el ángulo norte del Partido. 
El suelo es rico en rocas graníticas que se encuentran a ras de superficie. Esto ha permitido una importante industria de la piedra, al tiempo que se destaca la fertilidad de la tierra, por lo que son importantes la ganadería y la agricultura

El Partido es integrado por las localidades de Sierra Chica, Colonia Hinojo, Hinojo, Sierras Bayas, Colonia San Miguel, Colonia Nieves, Cerro Sotuyo, La Providencia, Loma Negra, Espigas, Recalde, Santa Luisa, Durañona, Pourtalé, Rocha, Mapis, Muñoz, Iturregui y Blanca Grande.

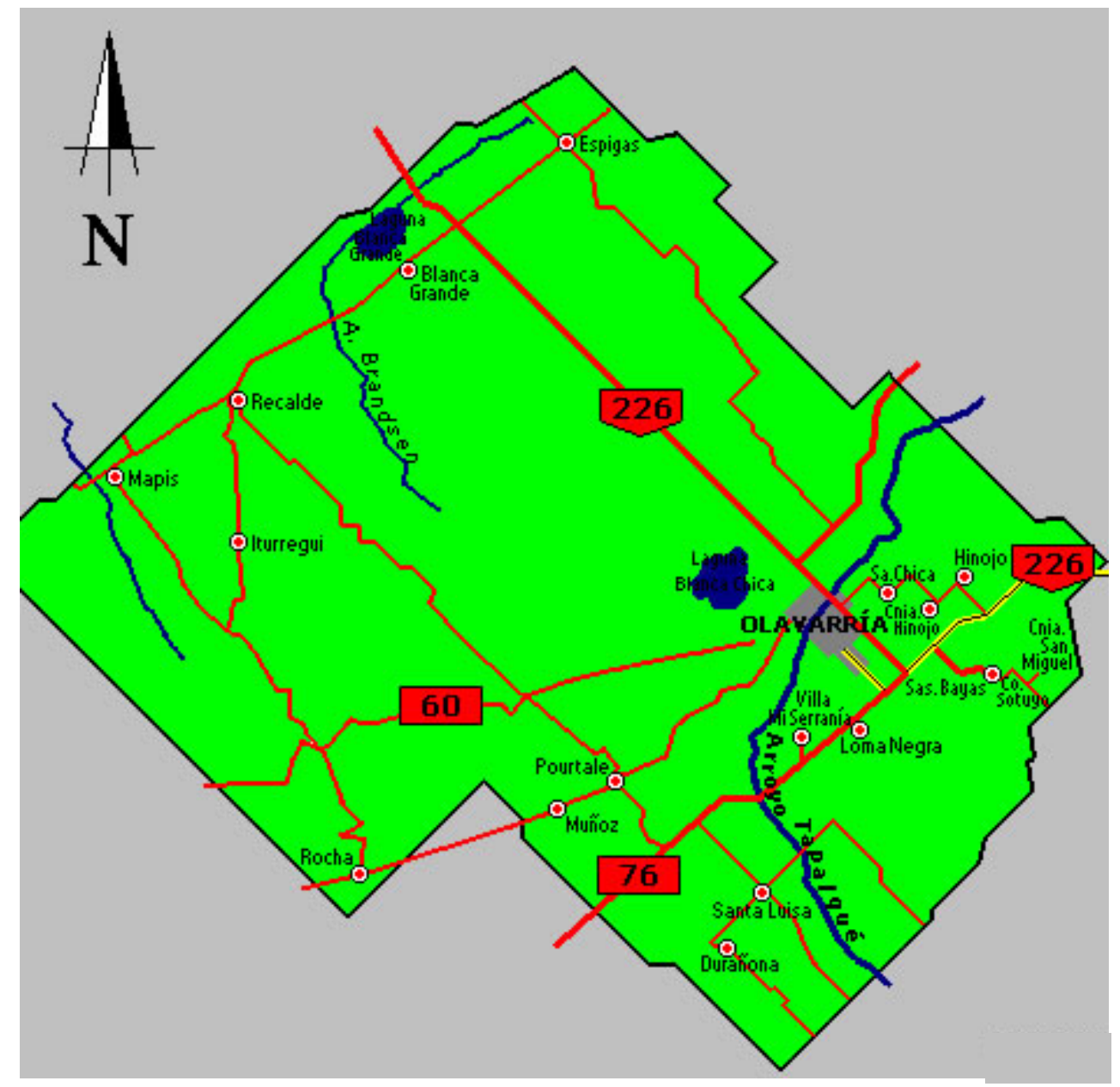

Gráfico 2: Partido de Olavarria, sus localidades

- Superficie partido en $\mathrm{km}^{2}: 7715$.

- Datos sociodemográficos

Población total (hab.): 103.961

\% pobl. (Necesidades Básicas Insatisfechas (NBI): 8,31 
$\%$ pobl. con cloacas : 46,7

$\%$ pobl. con agua potable: 71

$\%$ analfabetismo: 0,68

$\%$ desocupación: 11,3

Densidad poblacional (hab. $\left./ \mathrm{km}^{2}\right):, 54$

- Matrícula total de alumnos de primero a quinto grado de la escuela

primaria: 5473 , correspondiendo el $81 \%$ a establecimientos estatales.

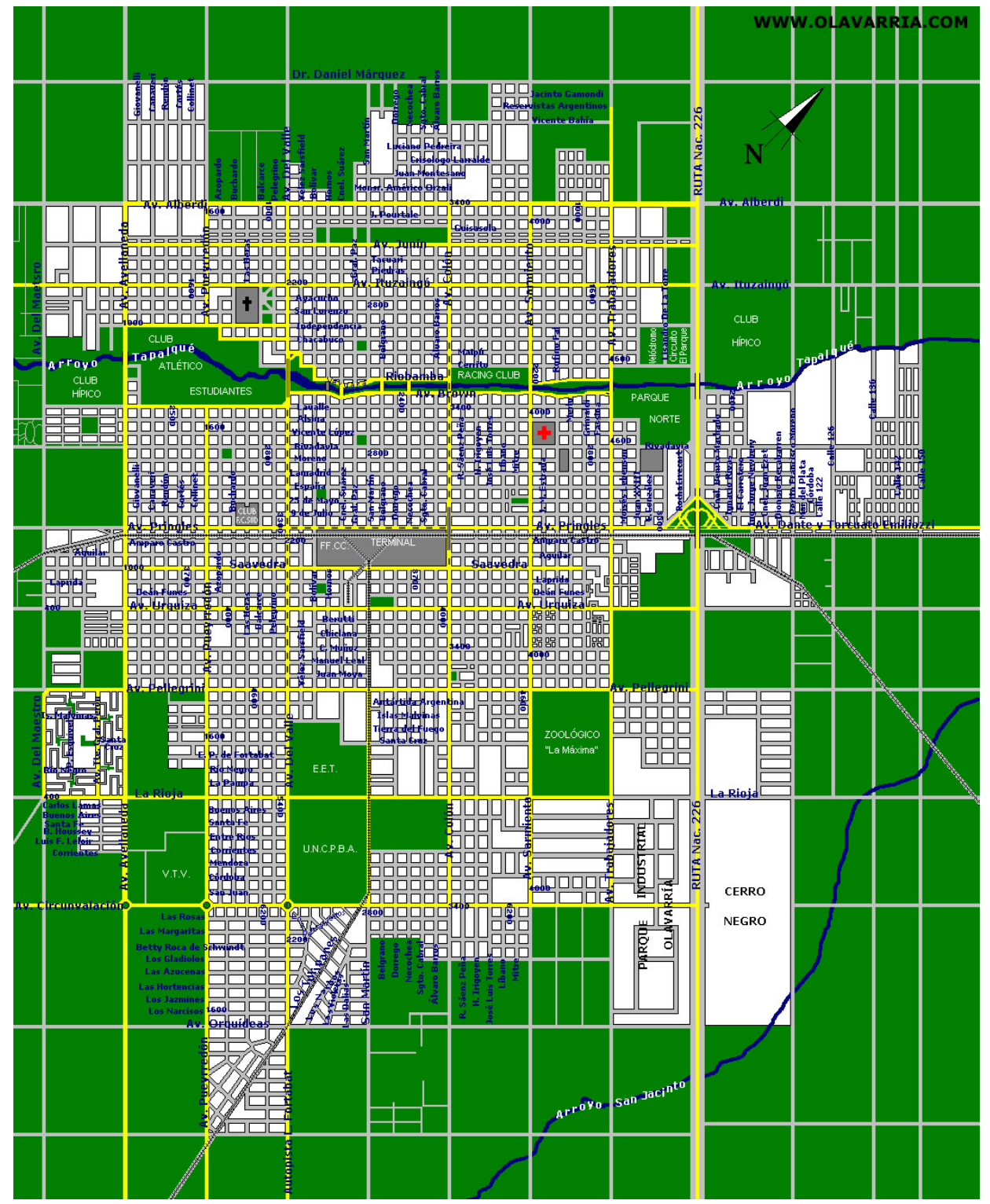

Gráfico 3: Plano de la ciudad de Olavarría 


\subsection{UNIVERSO DE ESTUDIO}

Se estudió una muestra representativa, seleccionada al azar, de la población de niños 6 a 10 años de ambos sexos del Partido de Olavarría Provincia de Buenos Aires, Argentina que concurren a establecimientos escolares (públicos y privados).

El tamaño muestral se determinó considerando una prevalencia de obesidad en el grupo estudiado de $20 \%$, con una precisión del 3,2\% y un nivel de confianza del $95 \%$ según la fórmula:

$\mathrm{n} \geq 4\left(\mathrm{z}_{\alpha / 2}\right)^{2} \mathrm{p}(1-\mathrm{p}) / \mathrm{I}^{2}$

donde $\mathrm{z}_{\alpha / 2}=$ valor crítico para un nivel de confianza 1- $\alpha$,

I=longitud del intervalo de confianza,

$p=$ prevalencia de obesidad $(20 \%)$.

El tamaño muestral estimado fue de 600 niños.

La relación entre las variables se estimó mediante test T de Student y coeficiente de correlación de Pearson.

Se tuvo en cuenta la localización de los establecimientos escolares:

-Centro: Grupo 1.

-Periferia: Grupo 2.

-Rurales y Serranos: Grupo 3.

Criterios de inclusión

Niños de ambos sexos que concurren a establecimientos escolares (públicos y privados) que acepten participar y con el consentimiento informado y asentimiento informado firmado.

Criterios de exclusión

Presencia de enfermedades crónicas.

\subsection{VARIABLES DE ESTUDIO}

- Demográficas 
Edad: niños de primer a quinto grado de escuela primaria, menores de 11 años.

Sexo: niños de ambos sexos.

- Socioeconómicas

Para determinar el nivel socio económico se definieron tres grupos siguiendo el criterio de ubicación geográfica de los establecimientos escolares ya que ello determina la matrícula que reciben. Asumiéndose una relación de ubicación geográfica y nivel socioecónomico.

Se establecieron las siguientes categorías:

Grupo 1: niños que concurrían a las escuelas que se encuentran entre las Avenidas Colón, Del Valle, Pringles y Brown, pertenecen al microcentro de la Ciudad (nivel medio-medio alto)

Grupo 2: niños que concurrían a las escuelas que se encuentran en el resto de la ciudad (nivel bajo y carenciado)

Grupo 3: niños que concurrían a las escuelas de las localidades Serranas y rurales.

- Antropométricas: Variables e indicadores

Presencia de sobrepeso y obesidad: Son niños que tiene un porcentaje de grasa aumentado. De acuerdo a la magnitud del aumento, se clasifica como sobrepeso y obesidad.

Indicador: Índice de Masa Corporal (IMC) (Peso/Talla ${ }^{2}$ ). Considerándose sobrepeso y obesidad de acuerdo a las tablas que se utilizan de NCHS, (National Center for Health Statistics) CDC, con las revisiones realizadas en el 2000 considerando como punto de corte los percentilos 85 para sobrepeso y 95 para obesidad ${ }^{(38-40)}$.

Presencia de Bajo Peso: valora el estado nutricional actual.

Indicador: Peso/Edad (P/E) se construye comparando el peso del niño en percentilo 50 de un estándar de referencia para sexo y edad según tablas de referencias nacionales e internacionales. Puntos de corte: < Percentilo 10 y < 2 Z score ${ }^{(38-40)}$. 
Presencia de retraso crónico del crecimiento (RCC): es una medida de crecimiento longitudinal estrechamente relacionada con la historia nutricional.

Indicador: Talla/Edad (T/E); se construye comparando la talla del niño con la talla en percentilo 50 de un estándar de referencia para sexo y edad según tablas nacionales e internacionales. Puntos de corte: < Percentilo 10 y $<-2$ Z score $^{(38-40)}$.

Presencia de masa grasa distribución central: es una medida de acumulación de grasa a nivel abdominal.

Indicador: Circunferencia de la cintura (CC). Se consideró como obesidad central cuando la CC fue $\geq$ al percentilo $90^{(24)}$.

Presencia de hipertensión: es una medida de la existencia de cifras tensionales arteriales elevadas.

Indicador: Tensión arterial (TA). Se consideró en riesgo de hipertensión aquel niño cuya TA estaba por encima del percentilo 90 y con hipertensión aquel niño cuya TA se encontraba por encima del percentilo 95 según tablas de edad, sexo y percentilo de talla ${ }^{(27)}$.

- Instrumentos y técnica de recolección de datos según procedimientos ${ }^{(38)}$ Peso

Fueron pesados con balanza C.A.M con precisión 100 gr.

Para determinar el peso corporal se pidió a los niños que portaran el mínimo de ropa posible, descalzos y habiendo evacuado vejiga. La balanza que se utilizó, se calibró antes de cada medición. Los niños fueron colocados de pie, en el punto medio de la báscula de frente al observador, vigilando que no se moviera y que no tenga ningún otro punto de apoyo.

La lectura del peso con el fiel en le centro de su recorrido, hasta los $100 \mathrm{gr}$. completos.

\section{Talla}

Los niños se midieron con altímetro movible de pared C.A.M con $1 \mathrm{~mm}$ de precisión (mín: $95 \mathrm{~cm}$, máx: 2.05 m). Sin calzado. 
Técnica: El sujeto se para de manera tal que sus talones, nalgas y cabeza estén en contacto con una superficie vertical. Los talones permanecen juntos, los hombros relajados y ambos brazos al costado del cuerpo para minimizar la lordosis. La cabeza debe sostenerse de forma que el borde inferior de la órbita esté en el mismo plano horizontal que el meato auditivo externo (plano de Frankfurt). Se desliza entonces la superficie horizontal hacia abajo a lo largo del plano vertical, hasta que toque la cabeza del sujeto. Se pide que haga una inspiración profunda, que relaje los hombros y se estire. Se efectúa la lectura hasta el último centímetro o milímetro completo ${ }^{(38)}$.

\section{Circunferencia de cintura}

Las medidas de circunferencia de cintura (CC) se tomaron en la zona más estrecha del abdomen, ubicando la cinta en el punto medio entre el reborde costal y la cresta ilíaca. Se utilizó una cinta métrica flexible y no elástica con el niño de pie, en expiración y los valores obtenidos se expresaron en centímetros (24).

\section{Tensión arterial}

La tensión arterial fue tomada siguiendo las normas de la American Hearth Association ${ }^{(27)}$. Se realizó con esfingomanómetro con reloj de precisión. Luego de permanecer sentado 5 minutos el niño, se coloca el brazo del niño formando un ángulo de 45 a 90 grados con el cuerpo, el brazo debe estar en ligera flexión, completamente relajado y el antebrazo apoyado sobre un plano horizontal que pase a la altura del corazón. El brazo debe estar libre de ropa, se aplica el manguito sobre la parte interna del brazo, de modo tal que cubra y rebase por detrás del trayecto arterial y que su borde inferior se encuentre a 2,5 $\mathrm{cm}$. por encima del codo, el ancho del manguito debe cubrir las 2/3 partes del brazo. Se utilizaron manguitos de $8 / 9 \mathrm{~cm}$. y de 10/12 cm. Se coloca el estetoscopio suavemente sobre la arteria humeral y se procede a insuflar el manguito a $20 \mathrm{~mm} \mathrm{Hg}$ por encima del nivel en el cual desaparece el pulso radial y luego desinflado a un promedio de 2 a $3 \mathrm{~mm} \mathrm{Hg}$ por latido. Se considera tensión arterial sistólica o máxima a la aparición de la onda de pulso (primer ruido de Korotkoff) .La tensión arterial diastólica o mínima es determinada cuando los ruidos arteriales desaparecen (5to. ruido de Korotkoff). 
Consideraciones Éticas

El protocolo fue aprobado por el Comité Institucional de Revisión de Protocolos de Investigación del Instituto de Desarrollo e Investigaciones Pediátricas (IDIP) del Hospital de Niños "Sor María Ludovica" de La Plata.

Dinámica del trabajo de campo

Se solicitó permiso por escrito al Consejo Escolar de Olavarría, una vez obtenido el mismo, se realizaron entrevistas con los Directores de los Establecimientos Escolares para explicar los objetivos del trabajo, su importancia y la colaboración por parte de los directivos, docentes, padres y alumnos de cada establecimiento.

En cada uno de ellos se entregaron los formularios de Consentimiento Informado para ser entregado a los padres y el asentimiento informado para aquellos niños que tuvieran más de 8 años.

Una vez cumplimentado esta etapa se diagramaron las visitas a los establecimientos para realizar el trabajo de campo.

En cada uno de ellos se contó con un despacho utilizado como consultorio, alejado del ruido y con los elementos necesarios para realizar las mediciones. Los niños fueron seleccionados al azar, por sorteo y si tenían firmado el consentimiento y el asentimiento eran medidos pesados y tomada la tensión arterial, acompañado por un docente o por los padres si deseaban estar presentes.

Los datos obtenidos fueron volcados a una base de datos especialmente diseñada para el trabajo de campo. 


\section{ANÁLISIS DE DATOS}

Las evaluaciones antropométricas, las mediciones de la circunferencia de la cintura y la tensión arterial fueron volcadas a una base de datos especialmente diseñada para el estudio.

El análisis analítico de la información se realizó mediante el programa de base de datos y estadísticas para la Salud Pública Epinfo 6 (CDC/who).

Las diferencias entre promedio y porcentaje se analizaron mediante el test de ANOVA y Chi cuadrado o prueba exacta de Fisher.

\section{RECURSOS HUMANOS}

- Médica Cardióloga Infantil. Médica Nora Elisabet Zeberio, de la ciudad de Olavarría.

- Licenciada en Nutrición: Lic. Agustina Malpeli. Instituto de Desarrollo e Investigaciones Pediátricas (IDIP) del Hospital de Niños de La Plata.

- Licenciada en matemáticas: Lic. María Apesteguia. Instituto de Desarrollo e Investigaciones Pediátricas (IDIP) del Hospital de Niños de La Plata.

- Licenciada en Servicio Social: Lic. Marta A Carballo. Dirección de Cultura y Educación de la Provincia de Bs.As., Jefatura Regional de la ciudad de Olavarria. 


\section{RESULTADOS}

Se evaluaron 555 niños menores de 11 años que cursaban entre $1^{\circ}$ y $5^{\circ}$ grado de Escuela Primaria.

El $45.8 \%$ (259) fueron mujeres.

Del total de niños evaluados se observó la siguiente distribución por clasificación de escuela; el 34.3\% concurrió a una escuela del Grupo 1, el $41.5 \%$ a una del Grupo 2 y el 22,3\% a una del Grupo 3.

En la Tabla 1 y Gráfico 4 se muestran los resultados antropométricos según indicador P/E y en la Tabla 2 y Gráfico 5 según indicador T/E, (prevalencia y distribución), para bajo peso y retraso crónico de crecimiento respectivamente (SAP).

\begin{tabular}{|l|l|l|}
\hline & \multicolumn{2}{|l|}{ Bajo Peso } \\
\hline & $<-2$ Z & $<$ Percentilo \\
& score & 10 \\
\hline SAP & 0.4 & 2.9 \\
\hline
\end{tabular}

Tabla 1: Porcentaje de niños con bajo peso (Indicador:P/E) 


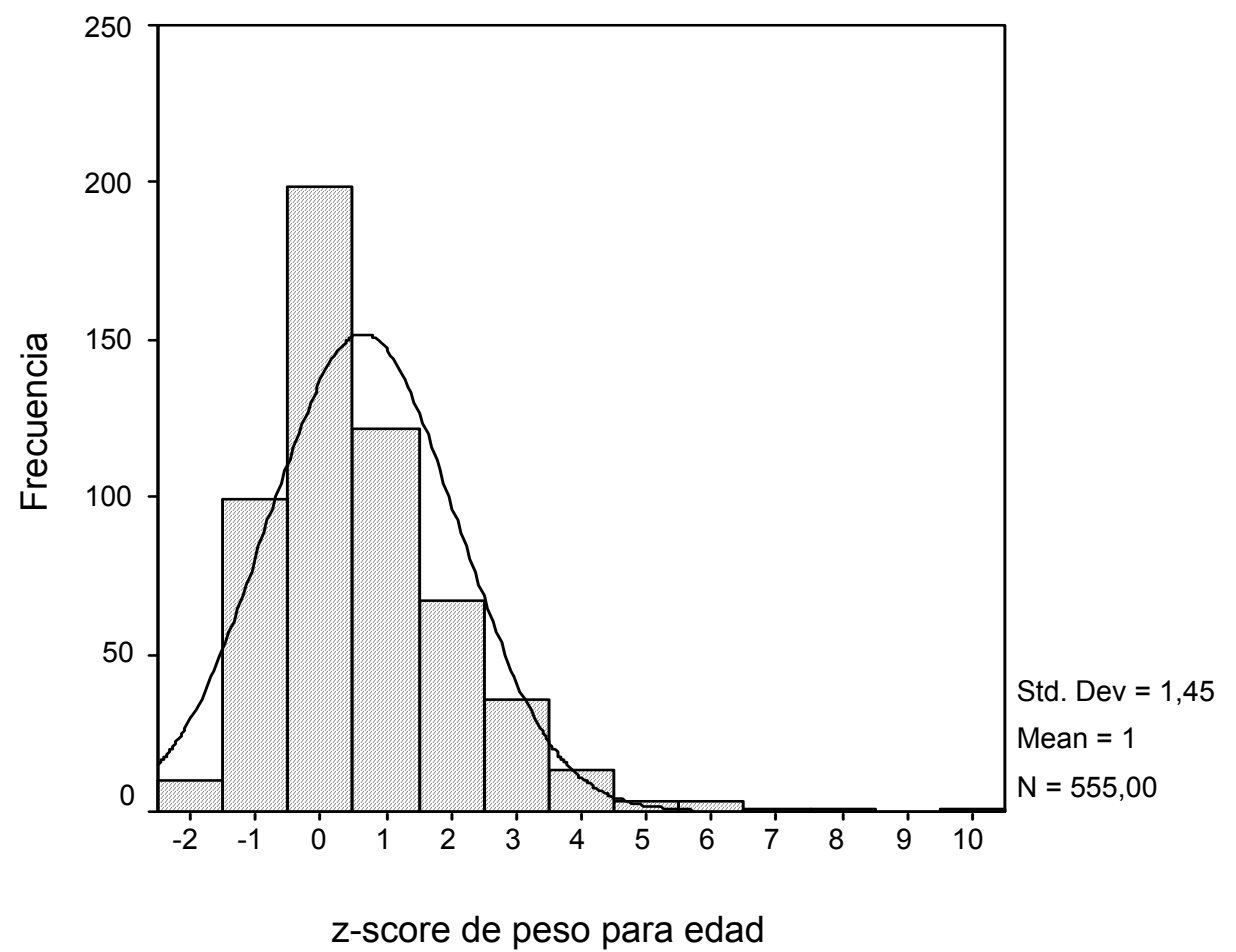

Gráfico 4: Distribución de la población según z-score P/E

\begin{tabular}{|l|l|l|}
\hline & RCC \\
\hline & $<-2$ Z & $<$ Percentilo \\
& score & 10 \\
\hline SAP & 4.1 & 10.1 \\
\hline
\end{tabular}

Tabla 2: Porcentaje de niños con RCC (Indicador T/E) 


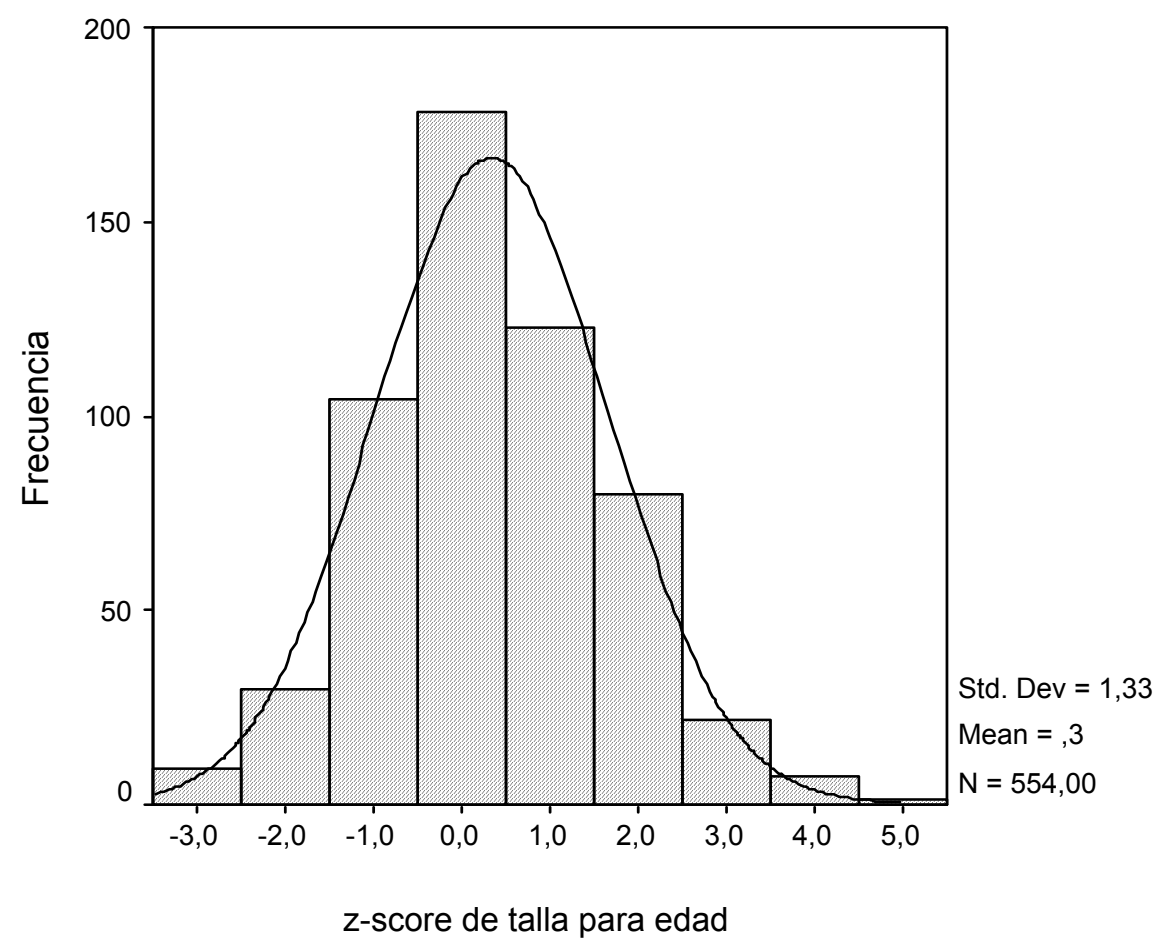

Gráfico 5: Distribución de Z store de Talla/Edad

En la Tabla 3 se observa el estado nutricional de la población estudiada por IMC. El $28.1 \%$ presentó sobre peso y obesidad.

La media de TAD fue de 58,7 \pm 7.63 .

\begin{tabular}{|l|c|}
\hline Estado Nutricional & Prevalencias \\
\hline Desnutridos & $5.8 \%$ \\
\hline Normales & $66.1 \%$ \\
\hline Sobrepeso & $18.6 \%$ \\
\hline Obesos & $9.5 \%$ \\
\hline
\end{tabular}


Tabla 3: Estado nutricional según IMC

En la Tabla 4 se observa el perímetro de cintura según edad en niños.

\section{Report}

CINTURA
\begin{tabular}{|l|l|r|r|}
\hline EDADA & Mean & N & Std. Deviation \\
\hline 5 & 55,5227 & 44 & 6,0865 \\
6 & 57,7551 & 49 & 6,0502 \\
7 & 60,2826 & 46 & 8,2615 \\
8 & 59,1026 & 39 & 6,0254 \\
9 & 64,7191 & 89 & 8,8420 \\
10 & 68,4286 & 28 & 10,0386 \\
Total & 61,1085 & 295 & 8,6847 \\
\hline
\end{tabular}

Tabla 4: Cintura según edad (niños)

En la Tabla 5 se observa el perímetro de cintura según edad en niñas.

\section{Report}

CINTURA
\begin{tabular}{|l|l|r|r|}
\hline EDADA & Mean & \multicolumn{1}{|c|}{ N } & Std. Deviation \\
\hline 5 & 55,7647 & 34 & 5,0755 \\
6 & 57,5918 & 49 & 6,9520 \\
7 & 61,2308 & 52 & 7,3207 \\
8 & 64,7619 & 42 & 9,2652 \\
9 & 62,1296 & 54 & 7,4582 \\
10 & 65,3214 & 28 & 7,0188 \\
Total & 61,0270 & 259 & 7,9706 \\
\hline
\end{tabular}

Tabla 5: Cintura según edad (niñas)

En las Tablas 6 y 7 se muestran las prevalencias de Bajo peso y RCC de la población diferenciado por categorías de escuelas. Las diferencias halladas entre grupos escolares no fueron estadísticamente significativas.

\begin{tabular}{|l|l|l|}
\hline P/E & \multicolumn{2}{|c|}{ Bajo Peso } \\
\cline { 2 - 3 } & $\begin{array}{l}<-2 Z \\
\text { score }\end{array}$ & $<$ Percentilo10 \\
\hline Grupo 1 & $0.5 \%$ & $2 \%$ \\
\hline
\end{tabular}




\begin{tabular}{|l|l|l|}
\hline Grupo2 & - & $3 \%$ \\
\hline Grupo 3 & $0.8 \%$ & $4 \%$ \\
\hline
\end{tabular}

Tabla 6: Prevalencia de bajo peso según grupos de categorías de escuela (SAP)

\begin{tabular}{|l|l|l|}
\hline \multirow{2}{*}{ T/E } & \multicolumn{2}{|c|}{ RCC } \\
\cline { 2 - 3 } & $\begin{array}{l}<-2 \mathrm{Z} \\
\text { score }\end{array}$ & $<$ Percentilo10 \\
\hline Grupo 1 & $3.6 \%$ & $8.2 \%$ \\
\hline Grupo2 & $6 \%$ & $12.4 \%$ \\
\hline Grupo 3 & $1.6 \%$ & $8.7 \%$ \\
\hline
\end{tabular}

Tabla 7: Prevalencia de RCC según grupos de categorías de escuela (SAP)

En la Tabla 8 se observan el estado nutricional por IMC según grupo de escuelas. Se observó una diferencia de sobrepeso y obesidad entre el grupo 1 y 2 de $10.1 \%$ ( $p=0.071)$. 


\begin{tabular}{|l|l|l|l|}
\hline & \multicolumn{3}{|l|}{ Estado nutricional por IMC } \\
\cline { 2 - 4 } & Desnutridos & Normales & $\begin{array}{l}\text { Sobrepeso y } \\
\text { Obesos }\end{array}$ \\
\hline Grupo 1 & $3.6 \%$ & $62.9 \%$ & $33.5 \%$ \\
\hline Grupo2 & $6 \%$ & $70.6 \%$ & $23.4 \%$ \\
\hline Grupo 3 & $8.7 \%$ & $62.7 \%$ & $28.6 \%$ \\
\hline
\end{tabular}

Tabla 8: Estado nutricional por IMC según grupo escolar

En los Gráficos 6 y 7 los Z- score P/E y de T/E respectivamente por grupos de escuelas.

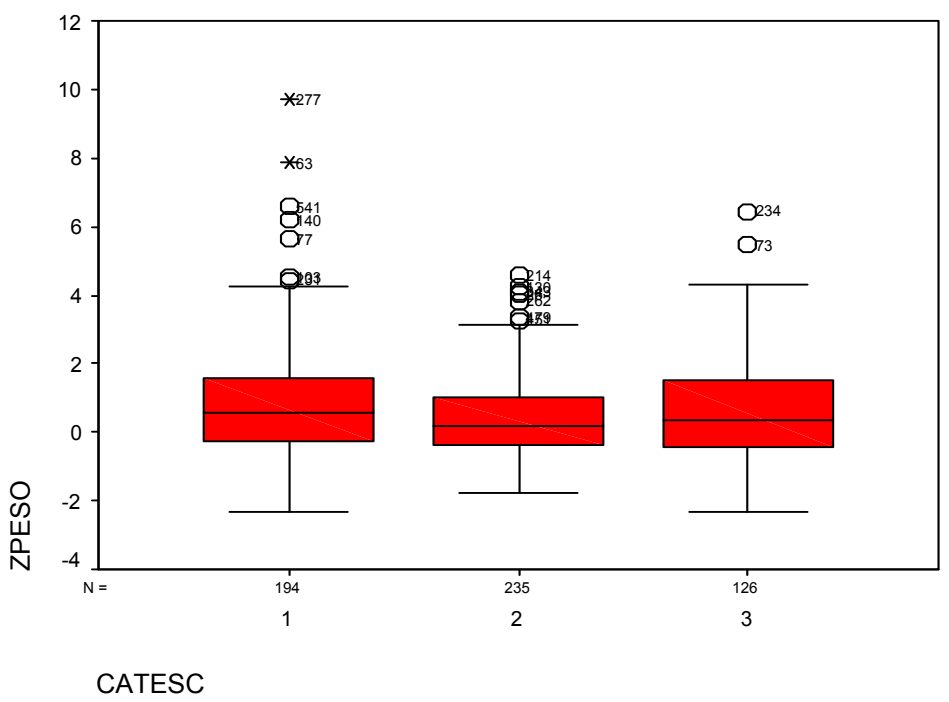

Gráfico 6: z-score de peso/E en cada grupo escolar 


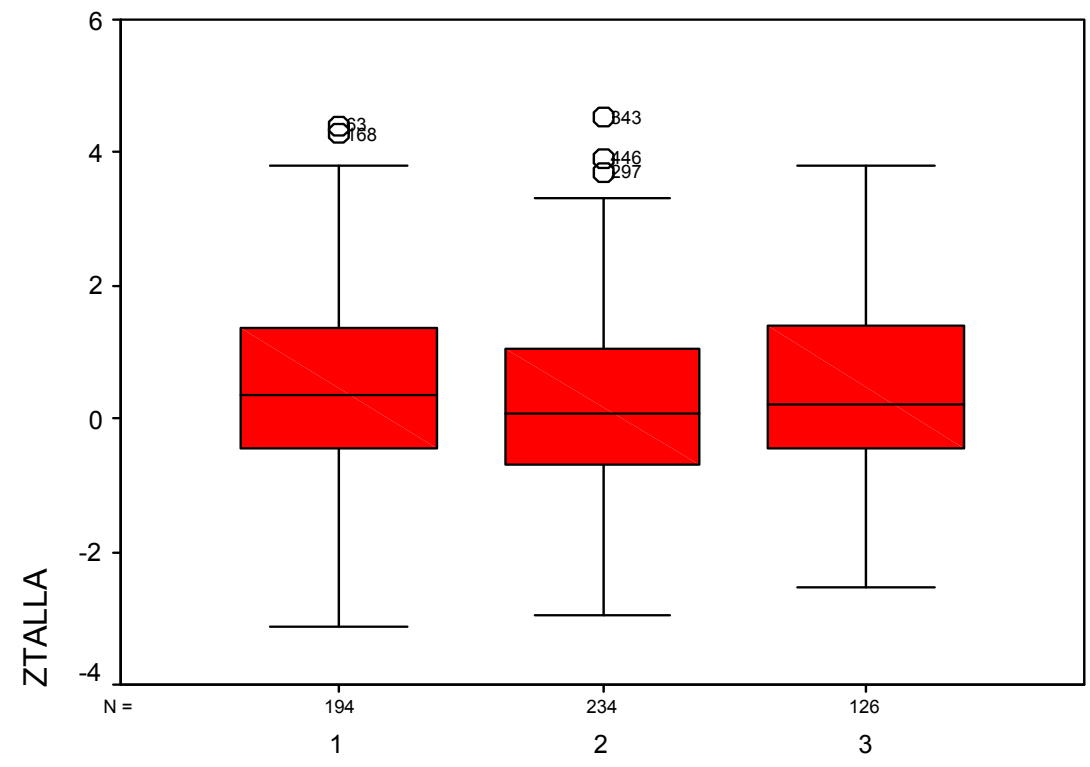

CATESC

Gráfico 7: z-score de T/E en cada grupo escolar

Cuando se analizaron las correlaciones entre tensión arterial diastólica y z-score de peso/edad, IMC y perímetro de cintura se halló una correlación positiva de $r=0.250, \quad(p=0.000), r=0.247,(p=0.000)$ y $r=0.325, p=0.000)$ respectivamente.

Se dividió a la población en 2 grupos según estado nutricional: uno, Bajo peso y Normales, y otro Sobrepeso y Obesidad, y se estudió la relación entre Tensión arterial sistólica y diastólica con sexo, edad y cintura en ambos grupos, construyendo modelos de regresión lineal.

En el ajuste de un modelo para TAS la variable sexo no resultó estadísticamente significativa, al eliminarla queda el modelo que se describe, más adelante, en la Tabla 12. Este modelo indica que TAS depende linealmente de la edad, por cada año de edad el valor medio de TAS se incrementa en aproximadamente $2,74 \mathrm{~mm} \mathrm{Hg}$ y de la cintura, cada cm más de cintura implica un incremento de $0,29 \mathrm{~mm} \mathrm{Hg}$ en TAS media, además en el grupo con sobrepeso u obesidad la TAS media es $1,87 \mathrm{~mm} \mathrm{Hg}$ superior que en los niños con estado nutricional normal. 
Al ajustar un modelo lineal para TAD, sexo y estado nutricional no resultaron significativas, al eliminarlas se obtuvo el modelo de la Tabla 13. Este modelo indica que la TAD también depende de la edad, aunque por cada año de edad el valor medio de TAD se incrementa en solo aproximadamente 1,10 $\mathrm{mm} \mathrm{Hg}$; y cada $\mathrm{cm}$ más de cintura implica un incremento de $0,20 \mathrm{~mm} \mathrm{Hg}$ en TAD media.

En los Gráficos 8, 9, 10 y 11 se observa la relación de TAS y TAD con edad y con cintura.

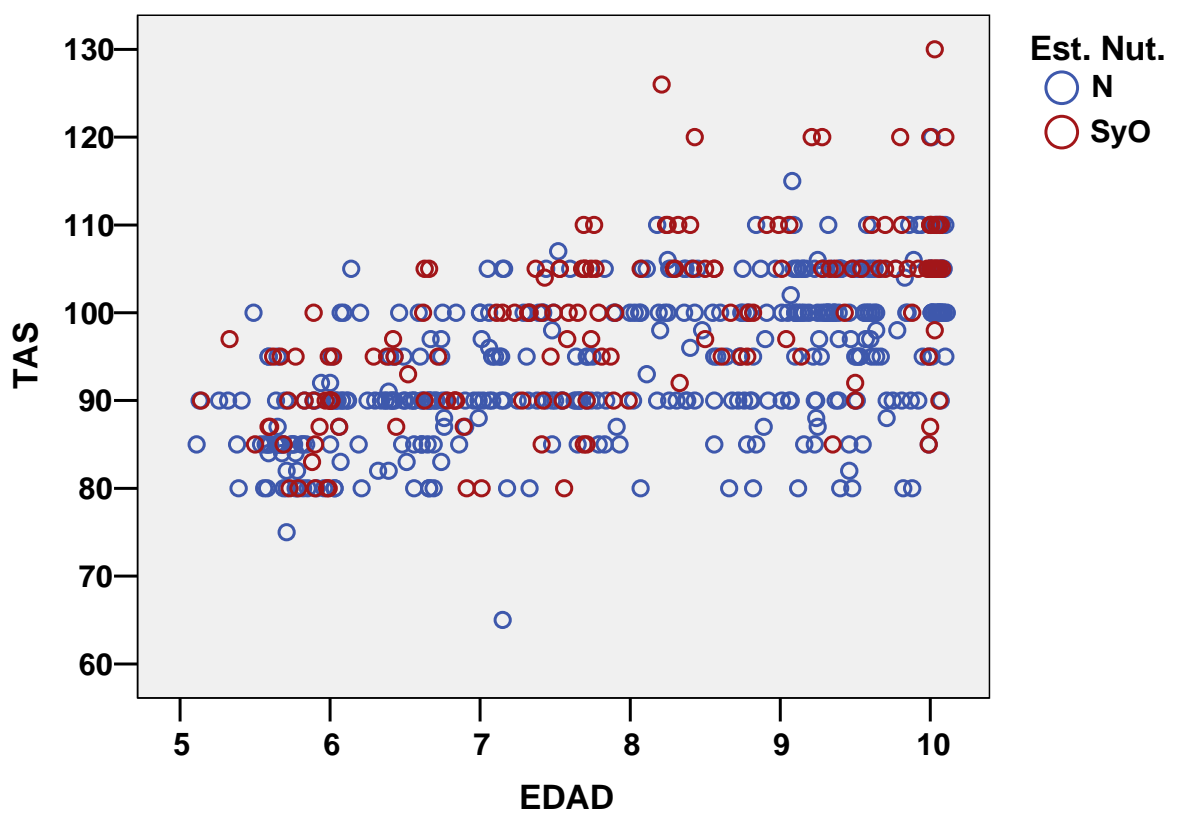

Gráfico 8: Relación TAS, Edad y Estado Nutricional 


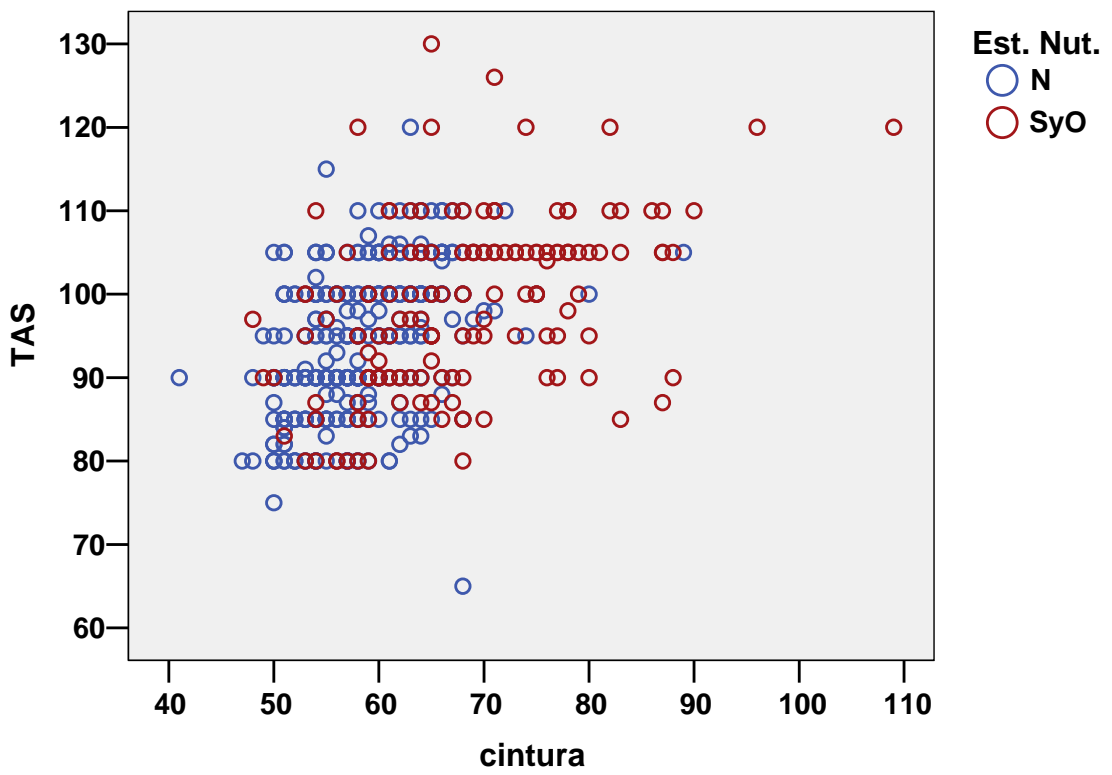

Gráfico 9: Relación TAS, C. Cintura y Estado Nutricional

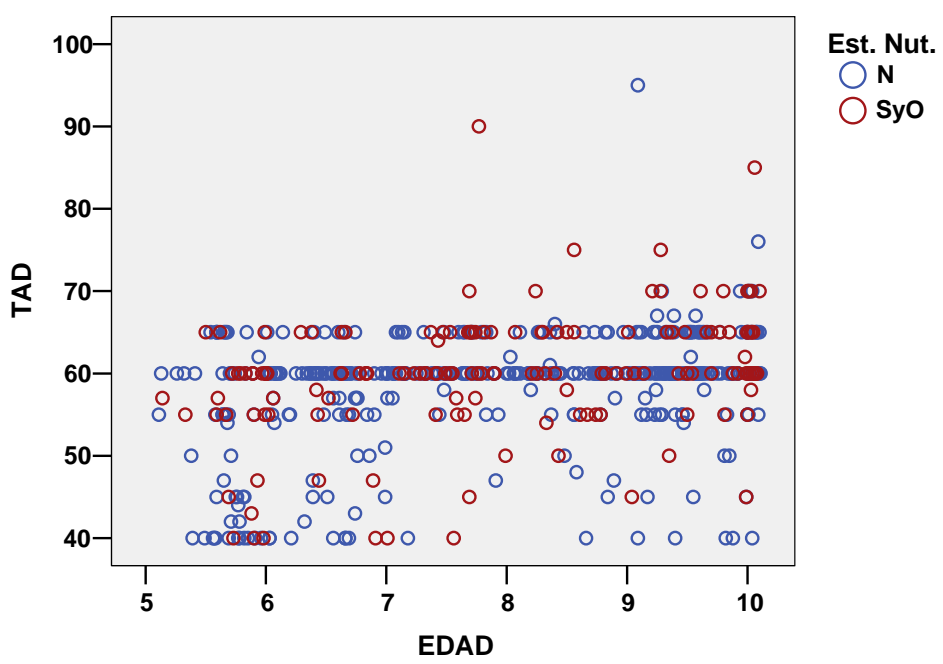

Gráfico 10: Relación TAD, EDAD y Estado Nutricional 


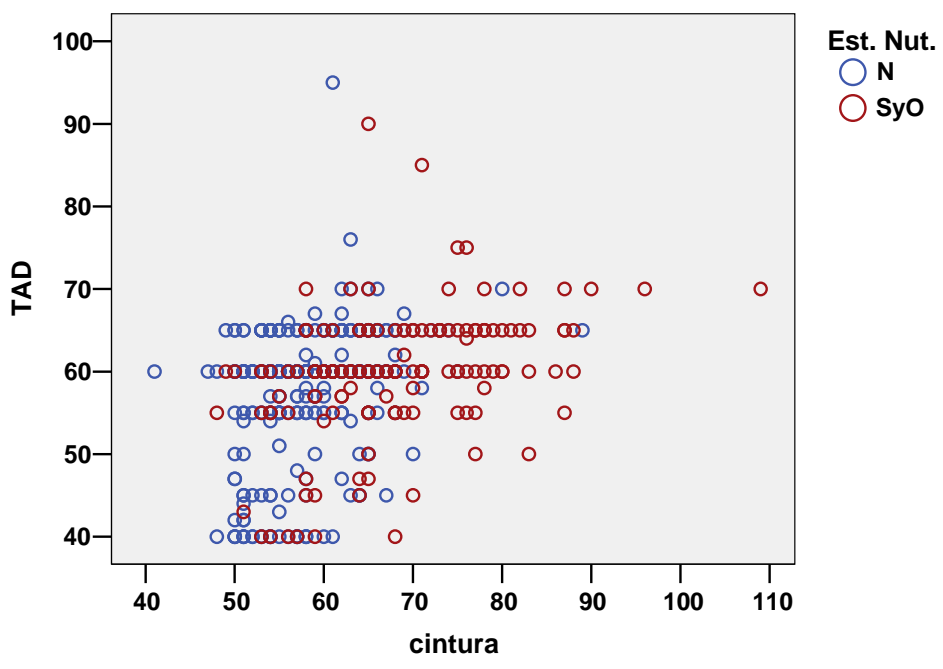

Gráfico 11: Relación TAD, C. Cintura y Estado Nutricional

Según estos modelos la TAD no es tan influenciada por la edad y la obesidad (según cintura) como la TAS

Se clasificó a la población estudiada de acuerdo al percentil 90 de cintura ${ }^{(17)}$. Se define obesidad central cuando la $C C$ es mayor o igual al percentil 90.

En la Tabla 9 se observa la distribución de la obesidad central según sexo. En las niñas hay un $15.1 \%$ de obesidad central y en los niños un $13.2 \%$.

SEXO * OBESC Crosstabulation

\begin{tabular}{|c|c|c|c|c|}
\hline & \multicolumn{2}{|c|}{ OBESC } & \multirow[b]{2}{*}{ Total } \\
\hline & & 1 & 2 & \\
\hline \multirow[t]{4}{*}{ SEXO } & Count & 39 & 220 & 259 \\
\hline & $\%$ within SEXO & $15,1 \%$ & $84,9 \%$ & $100,0 \%$ \\
\hline & Count & 39 & 257 & 296 \\
\hline & $\%$ within SEXO & $13,2 \%$ & $86,8 \%$ & $100,0 \%$ \\
\hline \multirow[t]{2}{*}{ Total } & Count & 78 & 477 & 555 \\
\hline & $\%$ within SEXO & $14,1 \%$ & $85,9 \%$ & $100,0 \%$ \\
\hline
\end{tabular}

1: Niños con obesidad central; 2: Niños sin obesidad central F: femenino; M: masculino

Tabla 9: Distribución de la obesidad central según sexo 
En la Tabla 10 se observa la comparación de la media de TAS y TAD entre los niños con obesidad (1) y sin obesidad central (2) La media de TAS fue superior en el grupo con obesidad central $(p=0.001)$. Del mismo modo se observó que la TAD $(p=0.002)$ fue superior en ese grupo.

Group Statistics

\begin{tabular}{|ll|r|r|r|r|}
\hline & OBESC & $\mathrm{N}$ & Mean & Std. Deviation & $\begin{array}{c}\text { Std. Error } \\
\text { Mean }\end{array}$ \\
\hline TAS & 1 & 78 & 98,5256 & 9,9736 & 1,1293 \\
& 2 & 477 & 94,9371 & 8,9113 &, 4080 \\
\hline TAD & 1 & 78 & 61,1154 & 6,4526 &, 7306 \\
& 2 & 475 & 58,4147 & 7,3641 &, 3379 \\
\hline
\end{tabular}

1: Niños con obesidad central; 2: Niños sin obesidad central Tabla 10: TAS y TAD, según presencia o no de Obesidad central

Se analizo la presencia de obesidad central en cada grupo de escuelas. Las diferencias halladas no fueron estadísticamente significativas. Los resultados se observan en la Tabla 11.

CATESC * OBESC Crosstabulation

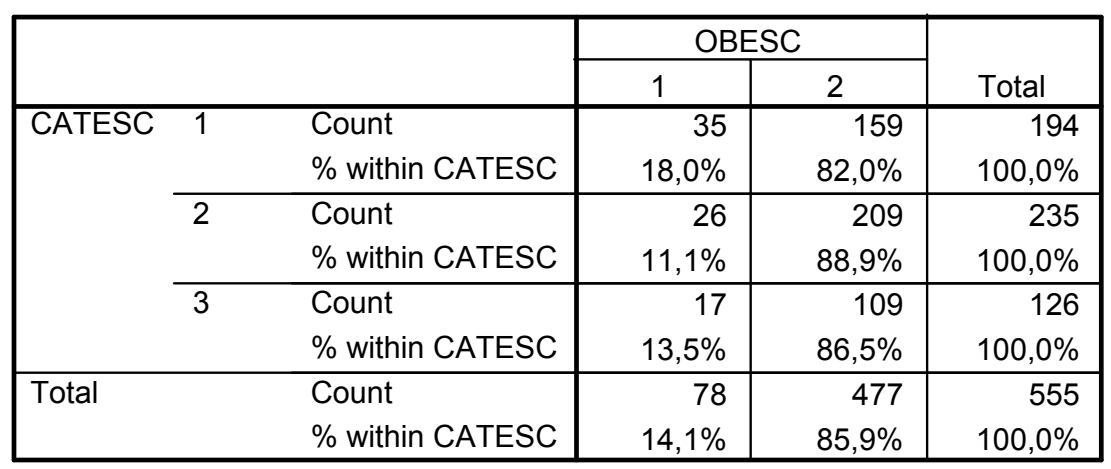

1: Niños con obesidad central; 2: Niños sin obesidad central Catesc: Categorías de escuelas

Tabla 11: Obesidad central según categorías de escuelas 
Finalmente, se presentan las Tablas 12 y 13, anteriormente referenciadas acerca de los coeficientes de edad, cintura y estado nutricional en los modelos de regresión lineal para TAD y para TAS.

\begin{tabular}{|l|r|r|}
\hline Variable & Coeficiente & p-valor \\
\hline Edad & 2,737 & 0,000 \\
\hline cintura & 0,288 & 0,000 \\
\hline EN (sobrepeso y obesidad) & 1,868 & 0,023 \\
\hline
\end{tabular}

$\mathrm{R}^{2}=0.402$

Tabla 12: Coeficientes de Edad, Cintura y Estado Nutricional, en el modelo de regresión lineal para TAS

\begin{tabular}{|l|r|r|}
\hline Variable & Coeficiente & p-valor \\
\hline Edad & 1,095 & 0,000 \\
\hline cintura & 0,204 & 0,000 \\
\hline$R^{2}=0.148$
\end{tabular}

Tabla 13: Coeficientes de Edad y Cintura, en el modelo de regresión lineal para TAD 
Limitaciones del estudio:

La relación asumida entre localización de la escuela y nivel socioecónomico podría tender a algún error de interpretación del nivel socio económico.

La localización de las escuelas rurales que, si bien carecen de algunos indicadores de necesidades básicas insatisfechas (cloacas, agua de red) no fueron considerados de bajos recursos por que los recursos de alimentos son suficientes.

\section{DISCUSIÓN}

Los resultados hallados en nuestra población de estudio en niños de 6 a 10 años ponen en evidencia que el principal problema nutricional es el sobrepeso (18.6\%) y la obesidad (9.5\%), alcanzando casi $30 \%$ de la muestra. Estos resultados se aproximan a los hallazgos de la Encuesta Nacional de Nutrición y Salud se encontró que en niños menores de 6 años la prevalencia general de obesidad es de aproximadamente $10 \%$ estimado por las curvas de la OMS, que sumado a la prevalencia de sobrepeso llega al $31 \%^{(11)}$. En un estudio realizado en Córdoba (tablas de referencia NCHS-OMS), que incluye niños de 5 a 8 años se observa una prevalencia de obesidad de $10.95 \%$ en los niños de 5 años y $10 \%$ en los de 8 años, que es similar a los hallazgos de nuestro estudio utilizando la misma herramienta de evaluación ${ }^{(41)}$.

Algunos estudios, focalizados en la pobreza, que utilizaron como referencia las curvas nacionales, realizados en la pasada década, mostraron cifras muy variables de prevalencia de obesidad y sobrepeso en niños en edad escolar. En Misiones en una población de niños de 6 a 11 años evaluados por el indicador $\mathrm{P} / \mathrm{T}$, el $9 \%$ de la población se ubicó por encima del percentilo 90 (42). Del mismo modo en el estudio realizado en Tierra del Fuego el $33 \%$ presentó un IMC por encima del percentil 85 y el 17\% por encima del percentil $95^{(16)}$.

También en estudios focalizados en pobreza utilizando tablas internacionales, los resultados en la localidad de A. Seguí, Pcia. de Bs. As, en

niños de 4-10 años el 12.9\% estaban por encima del percentil 85 de IMC ${ }^{(43)}$; en San Francisco Solano, Conourbano bonaerense en niños de 5-9 años, el $4.2 \%$ 
se hallaba por encima del percentil 85 (sobrepeso) y el $5 \%$ por encima del percentil 95 del IMC (Obesidad) ${ }^{(44)}$.

Si analizamos la situación socioecónomica se observó que en el estudio de Córdoba y de Salta los niños de mayores recursos tenían mayor prevalencia de sobrepeso que los de menores recursos. Nosotros hallamos que los niños de mayores recursos (Grupo 1 escolar) presentaban una tendencia de prevalencia mayor que el Grupo 2, aunque no fue significativa.

El estudio realizado por OMS/OPS revela una tendencia de aumento de la obesidad en países emergentes, especialmente en zonas urbanas ${ }^{(45)}$.

Tanto en Brasil como en Chile los resultados son similares a los hallados en nuestra población. El estudio en Brasil en niños de 8-10 años muestra un $16.9 \%$ por encima del percentil 85 del IMC y un $7.5 \%$ por encima del percentil $95^{(46)}$. En Chile en niños hasta 11 años el $18.5 \%$ se hallaba por encima del percentil $85^{(47)}$.

EI RCC se encuentra dentro de los valores esperados, los reportes para la región Sudamericana en el año 2004 fue de 5\% por debajo de -2 score de $Z$ de peso/Edad, y el hallado en nuestra población fue de $4.1 \%{ }^{(48)}$.

Los resultados hallados en nuestra población de las prevalencia de hipertensión arterial fue $1,081 \%$, similar a los reportes publicados de la población de los Estados Unidos ${ }^{(49)}$ La HTA en la infancia tiene una prevalencia baja (1-2\%), aumenta considerablemente durante la adolescencia y se asocia, especialmente, al sobrepeso ${ }^{(50,51)}$.

Nuestros resultados indican que la TAS y la TAD dependen linealmente de la edad, estado nutricional y perímetro de cintura.

Resulta interesante que en un estudio realizado en Corrientes, en niños mayores que los de nuestra población, cuyas edades fueron de 10 a 15 años, sus resultados muestran que la distribución de los valores medios de TA en ambos sexos y por grupo de edad se fueron incrementando a medida que aumentaban, la edad, el IMC y el nivel socioeconómico ${ }^{(51)}$.

En diversos estudios, algunos realizados e nuestro medio, se muestra una fuerte asociación entre obesidad e hipertensión arterial en niños.

Trifone y col., en el Hospital de Niños "Ricardo Gutiérrez" de Capital Federal encontraron en niños y adolescentes obesos una prevalencia de $6.9 \%$ de hipertensión arterial ${ }^{(52)}$. 
Deregibus M. y cols., reportaron resultados de estudios en entre los diferentes grupos étnicos donde se encontraron tensiones arteriales mas elevadas y aumento de la prevalencia de HTA en niños obesos en relación a niños delgados ${ }^{(53)}$.

En el estudio Bogalusa, los niños con sobrepeso tenían 4.5 y 2.4 veces más posibilidades de presentar cifras mas elevadas de TA sistólica y diastólica, respectivamente, que los niños sin sobrepeso ${ }^{(54)}$. Sorof y col., en un screening en una población de adolescentes de ocho escuelas públicas (TEXAS; EEUU), observaron que la prevalencia de hipertensión arterial sistólica era tres veces mayor en los obesos ${ }^{(55)}$.

Kivimaki y cols., señalan que el mayor contribuyente al aumento en la prevalencia de hipertensión en la edad pediátrica estaba directamente asociado con el aumento del mayor porcentaje de sobrepeso de la población ${ }^{(56)}$.

En un estudio realizado en Canadá, en una población rural de 4-17 años, encontraron Sobrepeso en el 18.15 de la muestra con $7.6 \%$ de hipertensión arterial y 11.45 de Obesidad con 7.45 de hipertensión ${ }^{(57)}$.

Las complicaciones metabólicas y el riesgo de enfermedades cardiovasculares tienen una correlación importante con el porcentaje de grasa visceral, denominada como obesidad central. La medición de la circunferencia de cintura es una medida sencilla y altamente sensible y específica de la masa grasa intrabdominal y se asocia con diferentes componentes del síndrome metabólico ${ }^{(17)}$. Hirschler y col. demostraron que la CC puede identificar niños con sobrepeso y Obesidad con riesgo de desarrollar complicaciones metabólicas y cardiovasculares ${ }^{(17)}$.

Nuestros resultados muestran una correlación positiva entre la obesidad central estimada por CC y la tensión arterial.

Genovesi y col. en Italia en un estudio de 4177 niños de 5 a 11 años investigaron el IMC y la medida de la CC para identificar riesgo de hipertensión y su influencia. Hallaron hipertensión en el $4.1 \%$ de la muestra y aumentaba con el aumento de peso, en el análisis multivariable mostraron que z-score tanto del IMC y la CC estaban significativamente relacionado con el riesgo de hipertensión, concluyendo que la hipertensión está fuertemente asociada con el aumento de peso y que la CC mejora la identificación de hipertensión en niños obesos $^{(58)}$. 
Maffei y col., en Italia, en un estudio con una población de niñas de 5 a 16 años con sobrepeso y obesidad hallaron una correlación positiva entre el aumento de la medida de la CC, la resistencia a la insulina e hipertensión arterial como índice preeditor de factores de riesgo cardiovascular y metabólico, enfatizando que la toma de la $\mathrm{CC}$ es una herramienta simple que ayuda a identificar subgrupos de niñas obesos con riesgos ${ }^{(59)}$.

En Suecia, Ruiz, J.R. y col. analizaron la asociación entre IMC, CC, y TA y estudio ergomérico entre 873 niños de 9 y 10 años. Encontraron que el aumento de la adiposidad central estaba positivamente asociada con la tensión arterial elevada y con el menor rendimiento cardiorrespiratorio al ejercicio ${ }^{(60)}$.

Otros estudios relacionaron obesidad, IMC, CC y TA con indicadores bioquímicos del síndrome metabólico. Si bien no fue objetivo de nuestro estudio, resulta de interés pues advierten además de otras complicaciones inherentes a la obesidad en niños y su impacto en el adulto, y nos dan el soporte científico para intervenir activamente en la prevención de estas complicaciones ${ }^{(61-63)}$.

Lee y col. en EUU realizaron la evaluación a 70 niños americanosafricanos y 97 caucásicos, midiendo, IMC, CC, TA, perfil lipídico y tejido graso abdominal. Encontraron que el IMC y la medición del CC estaban asociados con HTA, y que la medición asociada del IMC y CC agregaba un adicional a la medición en aumento del perfil lipídico ${ }^{(61)}$.

En Brasil Del Río Navarro y col estudiaron 1819 niños de 6 a 13 años midiendo edad, peso, talla, CC, TA, y niveles de glucosa y triglicéridos, calculando los percentilos de acuerdo a Standars Americanos y vieron que tanto el sobrepeso, la obesidad, la obesidad central estaban asociadas con hipertensión y niveles de triglicéridos altos, siendo los percentilos significativamente correlacionables ${ }^{(62)}$.

Hirschler y col. realizaron un estudio entre 5103 niños entre 4-13 años, para determinar cómo la medida de la circunferencia puede identificar anormalidades metabólicas, a todo el grupo realizaron medidas antropométricas $\mathrm{CC}$, y ta. $\mathrm{Y}$ a un subgrupo de 530 análisis de laboratorio, glucemia, perfil lipídico y prueba de insulina. El $6 \%$ era obeso, el $13.6 \%$ tenia sobrepeso, el síndrome metabólico estuvo presente en el $9.4 \%$ del total, (el SP 
$22.2 \%$ y los O $31 \%$,). Ellos encontraron que la CC mayor o igual al percentil 75 (th) puede ser un preeditor del síndrome metabólico en niños ${ }^{(17)}$.

Según nuestros resultados el Sobrepeso y Obesidad en los niños estudiados tienen un importante impacto sobre la Tensión Arterial Sistólica, y en menor medida sobre la Tensión arterial diastólica. Sin embargo la TAD fue significativamente superior en niños con sobrepeso y obesidad. La diferencia de la media hallada fue de $2.7 \mathrm{~mm}$ de $\mathrm{Hg}$.

Según un estudio poblacional muy importante realizado en EEUU, en una población adulta de 35 a 64 años de edad, la reducción de $2 \mathrm{~mm} \mathrm{Hg}$ en la TAD media de la población puede disminuir un $17 \%$ la prevalencia de hipertensión arterial, un $6 \%$ el riesgo de enfermedades coronarias y una reducción del $15 \%$ en los riesgos de accidentes cerebro vasculares y ataques isquémicos transitorio. O sea que una pequeña reducción de la distribución de la media de la presión arterial diastólica podría tener un gran impacto en salud pública sobre el número de enfermedades de origen cardiovascular ${ }^{(64)}$.

La observación de nuestros resultados en las diferencias de presión arterial diastólica halladas en niños en edad escolar con Sobrepeso y Obesidad pone en evidencia la necesidad de intervenciones de prevención desde la más temprana infancia para lograr estilos de vida saludable, que dependen de la actividad que se desarrolle sobre educación para la salud desde organismos de gobierno, así como la cooperación de la industria alimentaria.

\section{CONCLUSIONES}

La detección de Sobrepeso y Obesidad en la población infantil puede realizarse por métodos simples, accesibles y de bajo costo, fácilmente aplicables en atención primaria de la salud.

Nuestros resultados indican que el principal problema nutricional es el Sobrepeso (18.6\%) y la Obesidad $(9.5 \%)$.

Nuestros hallazgos indican que la TAS y la TAD dependen linealmente de la edad, el estado nutricional y el perímetro de cintura.

Nuestro estudio demuestra que la población escolar del partido de Olavarría tiene como problema principal nutricional el Sobrepeso y la Obesidad y es necesario definir políticas con programas de prevención y de educación 
a nivel Municipal, que incluya a la familia, a la escuela, a la comunidad, al Sistema de Salud y a las industrias alimentarias.

Agradecimientos: al Consejo Escolar de Olavarría, a la comunidad educativa, a los docentes, padres y alumnos que colaboraron para que se pudiera realizar la recolección de datos. Al instituto de Investigaciones Pediátricas del Hospital de Niños Sor María Ludovica (IDIP).A la Dra Ing.Silvia García y a mis amigos. 


\section{BIBLIOGRAFÍA}

${ }^{1}$ Calvo, E. Obesidad infantil y adolescente: un desafío para la Prevención. .Arch.argent.pediatr. 2002; 100(5)/355.

${ }^{2}$ Wang, Y.; Monteiro, C. y Popkin, B. Am J Clin Nutr.2002; 75:971-989.

${ }^{3}$ WHO. Physical status: the use and interpretation of anthropometry. Report of a WHO Expert Committee. WHO Technical Report Series, 1995. 854: p1-452.

${ }^{4}$ Popkin, B.M.The nutrition transition and its health implications in lower-income countries.P Health Nutr. 1998;1:5-21)

${ }^{5}$ Caballero Benjamin, MD.A. Nutrition Prardox-Underweigth and Obesity in Developing Countries. N.Engl J Med 352;15:1514-1516.

${ }^{6}$ Gortmaker, S.L. et al. Television viewing as a cause of increasing obesity among children in the US. Arch Pediatr Adolesc Med. 1996; 150:356-62

${ }^{7}$ Kromeyer-Hauschild, K.; Zellner, K.; Jaeger, U.; Hoyer, H. Prevalence of overweight and obesity among schoolchildren in Jena (Germany). Int J Obes. 1999; 23:1143-50.

${ }^{8}$ Rozowski, J.; Arteaga, A. El problema de la obesidad y sus características alarmantes en Chile. Rev Med Chile. 1997;125:1217-24.

${ }^{9}$ Agrelo, F.; Lobo, B.; Bazán, N.; Cinman, N.; Villafañe, L.; Actis, C.; Rodríguez, A. Prevalencia de obesidad en un grupo de escolares de bajo nivel socioeconómico. Arch.argent.pediatr. 1986; 84:5-12.

${ }^{10}$ Subcomision de Epidemiología y Nutrición. Consenso sobre factores de riesgo de enfermedad cardiovascular en pediatría. Obesidad. Archivo Argentino de Pediatría. 2005:103(3): 262-279.

${ }^{11}$ Ministerio de Salud de la Nación. Encuesta Nacional de Nutrición y Salud ENNyS. Documentos de Resultados. 2007: 52-64.

${ }^{12}$ Calvo, E. (ed.). Estudios antropométricos en la población infanto-juvenil. República Argentina 1993-1996. Dirección de Salud Materno Infantil. Ministerio de Salud. Buenos Aires.1999.

${ }^{13}$ Calvo E.; Carmuega, E., Gnazzo, N. y col. Evaluación del estado nutricional de la población de niños de 9 a 24 meses de edad residente en los partidos del Gran Buenos Aires. Arch.argent. pediatr. 1991; 89:132-141. 
${ }^{14}$ Díaz, A.; Jaquenod, M.; Rúgolo, E. y col. Encuesta nutricional a niños/as menores de 6 años de la provincia de Buenos Aires. Proyecto NUTRIABA. Resultados antropométricos. Abstract \# EN26, XII Congreso Latinoamericano de Nutrición. Buenos Aires, 2000.

${ }^{15}$ CESNI-CLACYD. Encuesta de salud, nutrición y desarrollo. Mamás y niños del 2000. Ciudad de Córdoba, 2000.

${ }^{16}$ CESNI. Proyecto Tierra del Fuego. Diagnóstico basal de salud y nutrición. Buenos Aires: Edición Fundación Jorge Macri, 1995.

${ }^{17}$ Hirschler, V.; Delfino, A. y cols. Es la circunferencia de cintura un componente del síndrome metabólico en la infancia? Archivo Argentino de Pediatría. 2005;103(1):7-13.

${ }^{18}$ Krebs, J.: American Academy of pediatrics. Comitee on Nutrition, Pediatrics. 2003:112(2):424-30.

${ }^{19}$ Koplan, J.P.; Liverman, C.; Kraak, V. (ed). Preveting Childhood Obesity. Health in the Balance.The National Academies Press, Washington DC, 2005.

${ }^{20}$ Stallings, V.; Yaktine, A. (ed). Nutrition Standards for Foods in Schools. Leading the Way Toward Healthier Youth. National academies Press, Washington DC, 2007.

${ }^{21}$ Rolland Cachera, M.F.; Bellisle, F.; Fricker, J.; Obesité Ricour, C.; Ghisolfi, J.; Putet, G.; Goulet, O. Traité de Nutrition Pediatrique. Ed. Maloine. Paris. 1993.

${ }^{22}$ Freedman, D.S., et al. Secular increase in relative weight and adiposity among children over two decades; the Bogalusa Heart study. Pediatrics. 1997; 99 (3):420-426.

${ }^{23}$ Lobstein, T.; Baur, L.; Uauy, R. Obesity in children and young people: a crisis in public health. International Obesity TaskForce. Obesity reviews 5(Suppl.1): 4-85.

${ }^{24}$ McCarthy, H.D.; Jarret, K.V.; Crawley, H.F. Development of waist circunference percentiles in Brittish children aged 5.0 to 16.9 years. Eur J. Clin Nutr. 2001; 55:902-907.

${ }^{25}$ Slyper, A. Childhood obesity, adipose tissue distribution and the pediatric practitioner. Pediatrics. 1998; 102: (4). 
${ }^{26}$ Falkner, B.; Daniels, S.; Horan, M.J.; Loggie, J.M., et al. Update on The Task Force Report (1987) on High Blood Presure in Children and Adolescents. Pediatrics. 1996; 98:649-658.

${ }^{27}$ National High Blood Pressure Education Program Working Group on High Blood Pressure in Children and Adolescents. The Fourth Report on the Diagnosis, Evaluation, and treatment of High Blood Pressure in Children and Adolescents. Pediatrics. 2004; 114: 555-576.

${ }^{28}$ Genovesi, S.; Antolini, L., et al. Usefulness of waist circunference for identification of childhood hypertensión...J. Hypertens. 2008, Aug; 26(8):156370.

${ }^{29}$ Maffeis, C.; Corciulo, N., et al. Waist circunference as a predictor of cardiovascular and metabolic risk factors in obese girls. Eur J Clin Nutr.2003, Apr; 57(4):566-72

${ }^{30}$ Ruiz, J.R.; Ortega, F.B., et al. Body fat associated with blood presure in school-aged girls with low cardiorespiratory fitness: the European Youth Heart Study. J. Hypertens.2007 Oct;25(10): 2027-34.

${ }^{31}$ Lee, S.; Bacha, F. Waist cicunference, blood presure, and lípido components of the metabolic syndrome. J. Pediatrics. 2006 Dec ;149(6):809-16.

${ }^{32}$ Del-Rio-Navarro B.E., et al. Obesity and metabolic risks in children. Arch Med Res. 2008 Feb;39 (2):215-21.

${ }^{33}$ Symonds, M.; Stephenson, T.; Budge H. Early determinants of cardiovascular disease: the role of early diet in later blood pressure control. Am J Clin Nutr. 2009;89(suppl):1518S-22S. Printed in USA. _2009 American Society for Nutrition.

${ }^{34}$ Peña, M.; Bacallao, J. La obesidad en la pobreza: Un problema emergente en las Américas. En: La obesidad en la pobreza. Un nuevo reto para la salud pública. OPS Publicación Científica. 2000. № 576.

${ }^{35}$ INDEC. Infancia y condiciones de vida. Encuesta especial para el diagnóstico y la evaluación de las metas sociales. Buenos Aires, 1995.

${ }^{36}$ O’Donnell, A. Una visión de la problemática nutricional de los niños argentinos. En: CESNI. Salud y calidad de vida de la niñez argentina. Bs. As., 1998: 119-156.

${ }^{37}$ Gortmaker, S.L., et al. Televisióon viewing as a cause of increasing obesity among children in the US 986-90. Arch Pediatr Adolesc Med. 1996; 150:356-62. 
${ }^{38}$ Comité de crecimiento y desarrollo. Guías para la evaluación del crecimiento. $2^{\mathrm{a}}$ edición Sociedad Argentina de Pediatría. Buenos Aires. 2001.

${ }^{39}$ De Onis, M.; Onyango, A.W.; Borghi, E.; Garza, C.; Yang, H. Comparation of the World Health Organization (WHO) Child Growth Standards and the national Center for health Statistics $/$ WHO international growth reference: implications for child health programmes. Public Health Nutr 2006. 9 (7): 942-7.

${ }^{40}$ CDC. National Center for Health Statistics.2000.CDC Growth Charts. United States.

${ }^{41}$ Chesta, M. Evaluación antropométrica Ciudad de Córdoba, Arch Argentino de Pediatría 2007;105 (2):101-108).

${ }^{42}$ Gullerian,A. y col. Situación nutricional de niños en contextos de pobreza de Puerto Iguazú,Misiones ,Argentina. Argentina. Arch Argent Pediatr 2006; 104(5):416-422.

${ }^{43}$ Malpeli, A. y col. Diagnóstico del estado Nutricional de Micronutrientes y evaluación antropométrica en una población infantil suburbana de la Provincia de Buenos Aires Ludovica (2006). VIII, 2:45-52.

${ }^{44}$. Dei-Cas,S y col. Sobrepeso y obesidad en la niñez.

Relación con factores de riesgo, Arch.argent.pediatr 2002; 100(5) 368-373.

${ }^{45}$ Uauy, R.; Albala, C.; Cain, J. Obesity Under in Latin America: Transiting from Under-to-overweight. J Nutr 2001; 131:893S-899S.)

${ }^{46}$ Triches, R.; Giugliani, E. Obesity, eating habits and nutritional knowledge among school children. Rev Saúde Pública, 2005;39 (4).

${ }^{47}$ Vio, F.; Albala, C.; Kain, J. Nutrition Transition in Chile revisited:mid-term evaluation of obesity goals for the period 2000-2010. Public Health Nutr; 20008 Apr;11 (4):405-12

${ }^{48}$ ACC/SCN, United Nations. Fifth report on the World Nutrition Situation, United Nations, Geneve, Switzerland. 2004.

${ }^{49}$ Mitsnefes, M.M. Hypertension in children and adolescents. Pediatr Clin North Am 2006; 53(3):493-512, viii

${ }^{50}$ Chobanian, A.V.; Bakris, G.L.; Black, H.R., et al. The Fourth Report on the Diagnosis, Evaluation and Treatment of High Blood Pressure in Children and Adolescents. Pediatrics. 2004; 114:555-576. 
${ }^{51}$ Poletti, O.H.; Pizzorno, J.A.; Barrios. L. Valores medios de tensión arterial en escolares de 10 a 15 años de la ciudad de Corrientes, Argentina. Arch argent Pediatr. 2006;104(3): 210-216.).

${ }^{5252}$ Trifone L y col, Hospital de Niños.R.Gutierrez. 34a Congreso Argentino de Pediatría. Córdoba 2006.

${ }^{53}$ Deregibus, M.; Haag, D.; Ferreiro, C. Consenso sobre factores de riesgo de enfermedad cardiovascular en pediatría. Arch Argent Pediatr 2005, vol 103 (4).348-366.

${ }^{52}$ Trifone L y col, Hospital de Niños.R.Gutierrez. 34 ${ }^{\text {a }}$ Congreso Argentino de Pediatría. Córdoba 2006.

${ }^{53}$ Deregibus, M.; Haag, D.; Ferreiro, C. Consenso sobre factores de riesgo de enfermedad cardiovascular en pediatría. Arch Argent Pediatr 2005, vol 103 (4).348-366.

${ }^{54}$ Freedman, D.S.; Dietz, W.H.; Srinivasan, S.R.; Berenson, G.S. The relation of overweight to cardiovascular risk factors among children and adolescents: the Bogalusa Heart Study. Pediatrics 1999;103:1175-1182.

${ }^{55}$ Sorof, J.M. ; Lai, D. ; Turner, J. ; Poffenbarger, T. ; Portman, R.J. Overweight, ethnicity, and the prevalence of hypertension in school-aged children. Pediatrics. 2004; 113: 475-482.

${ }^{56}$ Kivimaki, M.; Kinnunen, M.L.; Pitkanen, T.; Vahtera, J. y col.Contribution of early and adult factors to socioeconomic variation in blood pressure: thirtyfour-year follow-up study of school children. Psychosom Med 2004; 66 (2):1849.

${ }^{57}$ Salvadori, M.; Sontrop, J.M.; Garg, A.X.; Truong, J.; Suri, R.S.; Mahmud, F.H.; Macnab, J.J.; Clark, W.F. Department of Pediatrics, Children's Hospital, London, Ontario, Canada. Pediatrics. 2008 Oct;122(4):821-827.

${ }^{58}$ Genovesi, S.; Antolini, L., et al. Usefulness of waist circunference for identification of childhood hypertensión. J. Hypertens. 2008 Aug;26(8):1563-70.

${ }^{59}$ Maffeis, C.; Corciulo, N., et al. Waist circunference as a predictor of cardiovascular and metabolic risk factors in obese girls. Eur J Clin Nutr.2003 Apr;57(4):566-72.

${ }^{60}$ Ruiz, J.R.; Ortega, F.B., et al. Body fat associated with blood presure in school-aged girls with low cardiorespiratory fitness:the European Youth Heart Study. J. Hypertens.2007 Oct;25(10):2027-34. 
${ }^{61}$ Lee, S.; Bacha, F. Waist cicunference,blood presure,and lípido components of the metabolic syndrome. J. Pediatrics. 2006, Dec.;149(6):809-16.

${ }^{62}$ Del-Rio-Navarro B.E., et al, Obesity and metabolic risks in children. Arch Med Res. 2008 Feb;39 (2):215-21.

${ }^{63}$ Symonds, M.; Stephenson, T. and Budge, H. Early determinants of cardiovascular disease: the role of early diet in later blood pressure control. Am J. Clin Nutr 2009;89(suppl):1518S-22S. Printed in USA. _ 2009 American Society for Nutrition.

${ }^{64}$ Cook, N.; Cohen, J. Implications of small reductions in diastolic blood pressure for primary prevention. Arch Intern Med.1995 Apr 10;155(7):701-9. 


\section{RESUMEN}

La obesidad infantil constituye un serio problema de la salud pública en nuestro país, siendo uno de los problemas más comunes en niños y adolescentes, habiéndose documentado aumentos en su prevalencia en las últimas décadas .

Lo mismo ocurre en América Latina y el Caribe donde se notificó un aumento notable de la prevalencia de exceso de peso. Las tasas más altas se observan en EEUU y Europa, pero la tendencia de incremento es bastante generalizada en países tan diversos como Brasil y China.

En estudios recientes se analizaron las tendencias del sobrepeso en niños y adolescentes de 6 a 18 años, en 4 países, y en un período que va de 6 a 20 años, analizados según el índice de masa corporal (IMC) para la edad recomendados por la INTERNATIONAL OBESITY TASK FORCE.

La tendencia al aumento de la obesidad en los niños podría ser el resultado de cambios culturales y ambientales relacionados con la inactividad física en las sociedades modernas considerando que los riesgos están más relacionados con el medio ambiente, aspectos culturales o circunstancias individuales que herencia genética.

La combinación de peso insuficiente en niños y sobrepeso en adultos, con frecuencia coexiste en una misma familia, es un fenómeno relativamente nuevo hallado en países en vías de desarrollo que sufren la transición de nutrición, cambio de dietas, la distinta disponibilidad de alimentos y los cambios en el modo de vida. 
El acceso a la televisión, y a juegos de pantalla electrónica favorece el sedentarismo como otro dato negativo en la pérdida de peso.

Muchas complicaciones metabólicas y cardiovasculares, y algunas formas de cáncer asociados con obesidad en el adulto tienen sus comienzos en la infancia. La comprensión de las relaciones entre la obesidad del niño y el adolescente y la del adulto es un elemento muy valioso para tratar de implementar medidas adecuadas para su tratamiento y prevención.

La prevalencia de obesidad en los estudios realizados en Argentina en la última década oscila entre el $4.1 \%$ y $11 \%$, (año 2000).

En la Encuesta Nacional de Nutrición y Salud (ENNyS) realizada por el Ministerio de Salud de la Nación, se hace referencia a que la media nacional de prevalencia de obesidad fue $4.4 \%$ (IC 95\%, 3,8-5.1\%), (año 2000) en los niños y niñas entre 6 y 72 meses según curvas SAP. Pero evaluados según curvas de OMS, presentó obesidad el 10.4\% (IC 95\%, 9,3-11.5\%) de los niños y niñas entre 6 y 60 meses. La prevalencia de sobrepeso en el país es de 31,5\% (IC $95 \%, 30.2-32.9)$, proporción que no varía con la edad.

La información de prevalencia de sobrepeso y obesidad de nuestro país que existen son de diversos estudios con objetivos, metodologías y criterios de diagnósticos distintos. Sin embargo estos datos de los últimos 20 años sirven para expresar la transición epidemiológica que vive nuestro país y la región respecto de la convivencia de prevalencia de desnutrición (decreciente) y sobrepeso y obesidad (creciente). La mayoría de los estudios fueron realizados en niños menores de 6 años y/o mayores de 10 años y sólo la ENNyS fue representativa de la población general. 
El Consenso de la Sociedad Argentina de Pediatría sobre factores de riesgo de enfermedad cardiovascular en Pediatría plantea la prevalencia de la obesidad en niños en diferentes grupos etáreos. Sin embargo muestra la escasa información en niños de 6 a 10 años.

El único estudio realizado en escolares de la Ciudad de Buenos Aires de 6 a 13 años, no representativo de la población general, sin evaluar la situación socioeconómica muestra una prevalencia de sobrepeso del $29 \%$ y $12,3 \%$ de obesidad.

La probabilidad de la Obesidad Infantil (OI) de persistir en la adultez es del $20 \%$ a los 4 años de edad y $80 \%$ en la adolescencia.

Los hábitos de vida saludable se incorporan a la educación primaria escolar. El niño es participe y receptor de la educación.

El creciente número de consultas en edad pediátrica de obesidad, sobrepeso e hipertensión arterial en la práctica diaria crea la necesidad de contar con un diagnóstico preciso de las cifras de obesidad infantil, sobrepeso y su relación con la hipertensión arterial para realizar una adecuada intervención en políticas de salud nacionales. El desarrollo de políticas a nivel municipal necesita de información precisa de la problemática local para ser abordada.

Por eso se considera que la muestra del municipio debe representar a toda la población incluida en todos los estratos sociales. Uno de los sesgos de muchos de los estudios realizados en nuestro país es la focalización en algún estrato social (alto o bajo).

La relación entre la presencia de sobrepeso y obesidad y su impacto sobre el sistema cardiovascular fue establecida por métodos sencillos y no invasivos: indicadores antropométricos de estado nutricional y tensión arterial. 
En Argentina, como en la mayoría de los países del mundo occidental, padecemos una grave epidemia de enfermedades crónicas no transmisibles (ECNT), particularmente enfermedades cardiovasculares (ECV). Éstas encabezan las causas de muerte desde comienzos de la década del 70.

La obesidad es una enfermedad caracterizada por el aumento de la grasa corporal, definida como tal por la OMS en 1997. En la mayoría de los casos se acompaña de aumento de peso, cuya magnitud y distribución condicionan la salud del individuo. El sobrepeso es el exceso de peso con riesgo de obesidad.

La evaluación de la grasa corporal no puede medirse en los seres humanos directamente, por ello existen varias medidas indirectas para usar en niños y adolescentes. En la práctica clínica se promueven los indicadores Antropométricos: Peso según la talla $(\mathrm{P} / \mathrm{T})$; Pliegues cutáneos; Circunferencia de la cintura para valorar la distribución de la grasa, Índice de Masa Corporal.

El índice mas aceptado actualmente para evaluar la obesidad infantil es el IMC: Índice de Masa Corporal.

El índice de Masa Corporal o índice de Quetelet es una expresión del peso referido a la talla y se calcula dividiendo el peso corporal expresado en kilogramos por la talla elevada al cuadrado expresada en metros.

En niños el IMC guarda muy buena relación con la grasa corporal medida por pliegues cutáneos .

La OMS recomienda las tablas de referencias internacionales del National Center for Health Statistics (NCHS) y CDC para IMC, con las revisiones realizadas en el 2000 considerando como punto de corte los percentilos 85 para sobrepeso y 95 para obesidad . 
La circunferencia de la cintura es buen predictor de la distribución central de la grasa. Se asocia a mayor riesgo de padecer el síndrome metabólico .

De acuerdo a McCarthly se define obesidad central cuando la circunferencia de la cintura es igual o mayor al percentilo 90.

La hipertensión arterial se define como los niveles de TA sistólica (TAS) o diastólica (TAD) iguales o superiores al percentil 95 (P95) para una determinada edad, sexo y percentil de talla.

En los últimos veinte años ha surgido evidencia convincente que vincula factores de riesgo definidos en los adultos obesidad, sedentarismo, tabaquismo, hipertensión e hipercolesterolemia con procesos ateroescleróticos. En su patogenia se identifican factores hemodinámicos y trombóticos

La Obesidad Infantil fue asociado con dislipidemias, hipertensión arterial, Hiperinsulinismo, insulinorresistencia, intolerencia a la glucosa, DBT 2, ovario Opoliquístico, depresión, disminución de la autoestima, stress psicológico y estigmatización social, asma, apneas obstructivas del sueños, Síndrome de Pickwick, problemas ortopédicos (genu varun, epifisiolisis de la cabeza femoral), esteatohepatitis no alcohólica.

El incremento de la obesidad en pediatría ha ocasionado que la hipertensión se presente con mayor frecuencia en esta etapa de la vida, afectando 1 a $3 \%$ de los niños y hasta $10 \%$ en la adolescencia. 


\section{OBJETIVO GENERAL}

Realizar un estudio epidemiológico sobre Obesidad Infantil y Sobrepeso en niños de ambos sexos de 6 a 10 años que concurren a establecimientos escolares del Partido de Olavarría, provincia de Buenos Aires, Argentina.

Contribuir a la definición de políticas de salud a nivel Municipal.

\section{OBJETIVOS ESPECÍFICOS}

Determinar la prevalencia de Obesidad y sobrepeso infantil en una muestra representativa del partido de Olavarria.

Establecer la relación entre obesidad, sexo y edad.

Establecer la asociación entre la tensión arterial y el estado nutricional.

Establecer la correlación de la medida del perímetro abdominal con el estado nutricional.

\section{MATERIAL Y METODOS}

Tipo de estudio: EPIDEMIOLÓGICO DESCRIPTIVO Y ANALÍTICO Universo de estudio:

Se estudió una muestra representativa, seleccionada al azar, de la población de niños 6 a 10 años de ambos sexos del Partido de Olavarría 
Provincia de Buenos Aires, Argentina que concurren a establecimientos escolares (públicos y privados).

Criterios de inclusión

Niños de ambos sexos que concurren a establecimientos escolares (públicos y privados) que acepten participar y con el consentimiento informado y asentimiento informado firmado.

Criterios de exclusión

Presencia de enfermedades crónicas.

Variables de estudio:

Demográficas

Edad: niños de primer a quinto grado de escuela primaria, menores de 11 años.

Sexo: niños de ambos sexos.

Socioeconómicas: Para determinar el nivel socio económico se definieron tres grupos siguiendo el criterio de ubicación geográfica de los establecimientos escolares ya que ello determina la matrícula que reciben. Asumiéndose una relación de ubicación geográfica y nivel socioecónomico.

Antropométricas: Variables e indicadores

Presencia de sobrepeso y obesidad: Índice de Masa Corporal (IMC) (Peso/Talla ${ }^{2}$. Considerándose sobrepeso y obesidad de acuerdo a las tablas que se utilizan de NCHS, (National Center for Health Statistics) CDC, con las revisiones realizadas en el 2000 considerando como punto de corte los percentilos 85 para sobrepeso y 95 para obesidad. 
Presencia de masa grasa distribución central: se tomó la medida de la circunferencia de la cintura (CC). Se consideró como obesidad central cuando la CC fue $\geq$ al percentilo 90 .

Presencia de hipertensión: Se consideró en riesgo de hipertensión aquel niño cuya TA estaba por encima del percentilo 90 y con hipertensión aquel niño cuya TA se encontraba por encima del percentilo 95 según tablas de edad, sexo y percentilo de talla.

Las evaluaciones antropométricas, las mediciones de la circunferencia de la cintura y la tensión arterial fueron volcadas a una base de datos especialmente diseñada para el estudio.

El análisis analítico de la información se realizó mediante el programa de base de datos y estadísticas para la Salud Pública Epinfo 6 (CDC/who).

Las diferencias entre promedio y porcentaje se analizaron mediante el test de ANOVA y Chi cuadrado o prueba exacta de Fisher.

\section{Resultados}

Se evaluaron 555 niños menores de 11 años que cursaban entre $1^{\circ}$ y $5^{\circ}$ grado de Escuela Primaria.

El $45.8 \%$ (259) fueron mujeres.

Del total de niños evaluados se observó la siguiente distribución por clasificación de escuela; el $34.3 \%$ concurrió a una escuela del Grupo 1 , el $41.5 \%$ a una del Grupo 2 y el $22,3 \%$ a una del Grupo 3.

Los resultados hallados en nuestra población de estudio en niños de 6 a 10 años fueron: sobrepeso (18.6\%) y la obesidad $(9.5 \%)$, siendo el $28,1 \%$ de la muestra. Estos resultados se aproximan a los hallazgos de la Encuesta 
Nacional de Nutrición y Salud se encontró que en niños menores de 6 años la prevalencia general de obesidad es de aproximadamente $10 \%$ estimado por las curvas de la OMS, que sumado a la prevalencia de sobrepeso llega al $31 \%$.

Si analizamos la situación socioecónomica observamos que los niños de mayores recursos (Grupo 1 escolar) presentaban una tendencia de prevalencia mayor que el Grupo 2, aunque no fue significativa.

EI RCC se encuentra dentro de los valores esperados, los reportes para la región Sudamericana en el año 2004 fue de 5\% por debajo de - 2 score de $Z$ de peso/Edad, y el hallado en nuestra población fue de $4.1 \%$.

Los resultados hallados en nuestra población de las prevalencia de hipertensión arterial fue $1,081 \%$, similar a los reportes publicados de la población de los Estados Unidos. La HTA en la infancia tiene una prevalencia baja (1-2\%), aumenta considerablemente durante la adolescencia y se asocia, especialmente, al sobrepeso.

Nuestros resultados indican que la TAS y la TAD dependen linealmente de la edad, estado nutricional y perímetro de cintura.

Nuestros resultados muestran una correlación positiva entre la obesidad central estimada por CC y la tensión arterial.

Según nuestros resultados el Sobrepeso y Obesidad en los niños estudiados tienen un importante impacto sobre la Tensión Arterial Sistólica, y en menor medida sobre la Tensión arterial diastólica. Sin embargo la TAD fue significativamente superior en niños con sobrepeso y obesidad. La diferencia de la media hallada fue de $2.7 \mathrm{~mm}$ de $\mathrm{Hg}$. 
CONCLUSIONES

La detección de Sobrepeso y Obesidad en la población infantil puede realizarse por métodos simples, accesibles y de bajo costo, fácilmente aplicables en atención primaria de la salud.

Nuestros resultados indican que el principal problema nutricional es el Sobrepeso (18.6\%) y la Obesidad $(9.5 \%)$.

Nuestros hallazgos indican que la TAS y la TAD dependen linealmente de la edad, el estado nutricional y el perímetro de cintura.

Nuestro estudio demuestra que la población escolar del partido de Olavarría tiene como problema principal nutricional el Sobrepeso y la Obesidad y es necesario definir políticas con programas de prevención y de educación a nivel Municipal, que incluya a la familia, a la escuela, a la comunidad, al Sistema de Salud y a las industrias alimentarias. 
13. ANEXOS 
Autoridades del Consejo Escolar

Distrito Olavarría

S/D

De mi mayor consideración:

Me dirijo a Uds a fin de solicitarles autorización para realizar el trabajo de campo en las Escuelas dependientes del Consejo escolar Distrito Olavarría para el trabajo de Tesis de la Maestría en Salud Pública Orientación Establecimientos del Centro Interdisciplinario de la Facultad de Medicina de la Universidad Nacional de La Plata:

"Estudio epidemiológico de obesidad y sobrepeso en niños de ambos sexos de 6 a 10 años del Partido de Olavarría, Provincia de Buenos Aires, Argentina." con la Dirección del Dr. Horacio Federico González .

Sin otro particular y agradeciendo su colaboración saludo a Uds. muy atentamente.

Dra Nora E. Zeberio

Médica Cardióloga Infantil

MP 14749

PD: Adjunto Plan de Tesis 
Sr. Director

de la Maestría en Salud Pública .Orientación Establecimientos y Servicios de atención Médica.

Prof. Dr.Horacio Barragán

$\underline{\mathrm{S}} \mathrm{I} \quad \mathrm{D}$

De mi mayor consideración.

Tengo el agrado de dirigirme a ustedes con el fin de elevarles para su aceptación, el Plan de Tesis de la carrera de la Maestría en Salud Pública, Orientación Establecimientos y Servicios de Atención Médicas sobre el tema: "Estudio epidemiológico de obesidad y sobrepeso en niños de ambos sexos de 6 a 10 años del Partido de Olavarría, Provincia de Buenos Aires, Argentina." y solicitarles por intermedio de ésta, la Dirección del Dr. Horacio Federico González .

Sin otro particular, saludo a ustedes atentamente.

Dra Nora Elisabet Zeberio

Cardióloga Pediatra

Dr Horacio Federico González 
MAESTRIA EN SALUD PUBLICA. CENTRO INUS. FACULTAD DE MEDICINA UNIVERSIDAD NACIONAL DE LA PLATA.

\title{
Carta de Asentimiento OBESIDAD INFANTIL Y SOBREPESO
}

\begin{abstract}
ESTUDIO EPIDEMIOLOGICO DE OBESIDAD INFANTIL Y SOBREPESO EN NIÑOS DE 6 A 10 AÑOS DE EDAD EN EL PARTIDO DE OLAVARRIA QUE CONCURREN A ESTABLECIMIENTOS ESACOLARES.
\end{abstract}

Te invitamos a participar de un estudio que se está realizando en el Partido de Olavarría. Este estudio se realiza como trabajo Final de Tesis de la Maestría en Salud Pública de la Facultad de Medicina de la Universidad Nacional de La Plata. Será realizado por la Dra Nora Zeberio, cardióloga Infantil, bajo la Dirección del Dr. Horacio González, Director del Instituto de Desarrolllo e Investigaciones Pediátricas del Hospital de Niños de La Plata y está autorizado por las autoridades del Consejo Escolar de Olavarría.

El mismo consiste en un relevamiento de los niños de ambos sexos en edad escolar de 6 a 10 años que concurren a distintos Establecimientos Escolares del Partido de Olavarría, lo que permitirá tener una evaluación del estado nutricional de los niños.

Si te interesa participar es muy sencillo, similar a lo que tu pediatra realiza en los controles anuales para llenar las fichas escolares: peso, altura, medir la presión y medir la cintura, y lo haremos en un aula de la escuela que será destinada para el fin, pueden estar tus padres si lo deseas y será en forma individual. El exámen será realizado por la Dra Nora Zeberio

Estos datos permitirán conocer el porcentaje de Obesidad Infantil y Sobrepeso en Olavarria, la toma de tensión arterial, la presencia o no de hipertensión arterial y la medida de la cintura es un dato mas para la evaluación de la Obesidad.

Si fuese necesario serás informado y derivado a un especialista para el tratamiento y seguimiento.

Las planillas serán guardadas en el Instituto de Desarrollo e Investigaciones Pediátricas del Hospital de Niños de La Plata bajo criterios de confidencialidad respecto a su identidad.

La participación es voluntaria, gratuita y tenés la libertad de elegir participar o no. Si decides no participar esto no tendrás consecuencias sobre la atención de salud ni sobre los alimentos que recibes.

Nombre y Apellido de la participante:

DNI:

Firma:

Nombre y Apellido del padre/ madre o tutor:

DNI:

Firma

Nombre y Apellido del Investigador Principal:

DNI:

Firma:

Nombre y Apellido de testigo:

DNI:

Firma: 


\section{MAESTRIA EN SALUD PUBLICA. CENTRO INUS. FACULTAD DE MEDICINA UNIVERSIDAD NACIONAL DE LA PLATA.}

\section{Carta de Consentimiento Informado OBESIDAD INFANTIL Y SOBREPESO}

\section{ESTUDIO EPIDEMIOLOGICO DE OBESIDAD INFANTIL Y SOBREPESO EN NIÑOS DE 6 A 10 AÑOS DE EDAD EN EL PARTIDO DE OLAVARRIA QUE CONCURREN A ESTABLECIMIENTOS ESACOLARES.}

Lo invitamos a participar de un estudio que se está realizando en el Partido de Olavarría. Este estudio se realiza como trabajo Final de Tesis de la Maestría en Salud Pública de la Facultad de Medicina de la Universidad Nacional de La Plata .Será realizado por la Dra Nora Zeberio, cardióloga Infantil, bajo la Dirección del Dr. Horacio González, Director del Instituto de Desarrolllo e Investigaciones Pediátricas del Hospital de Niños de La Plata y está autorizado por las autoridades del Consejo Escolar de Olavarría.

El mismo consiste en un relevamiento de los niños de ambos sexos en edad escolar de 6 a 10 años que concurren a distintos Establecimientos Escolares del Partido de Olavarría, lo que permitirá tener una evaluación del estado nutricional de los niños.

Si Ud desea que su hijo/a participe el exámen consistirá en: control de peso, de la estatura, la tensión arterial y la circunferencia de cintura. Este exámen no es invasivo y no provoca ningún dolor o molestia para el niño/a. Es muy similar al que su Pediatra realiza en los controles anuales de Salud. Si Ud. desea estar presente en el momento del exámen se le avisará con antelación el día y la hora. El exámen será realizado por la Dra Nora Zeberio en la misma escuela, en un aula destinada para el fin, cuidando la privacidad e intimidad del niño/a y en forma individual. Estos datos serán volcados en una planilla donde constará fecha de nacimiento, domicilio y entidad escolar a la que concurre.

Estos datos permitirán conocer el porcentaje de Obesidad Infantil y Sobrepeso en Olavarria, la toma de tensión arterial, la presencia o no de hipertensión arterial y la medida de la cintura es un dato mas para la evaluación de la Obesidad.

Si fuese necesario será informado y derivado a un especialista para el tratamiento y seguimiento.

Las planillas serán guardadas en el Instituto de Desarrollo e Investigaciones Pediátricas del Hospital de Niños de La Plata bajo criterios de confidencialidad respecto a su identidad.

La participación es voluntaria, gratuita y tiene la libertad de elegir participar o no. Si decide no participar esto no tendrá consecuencias sobre la atención de salud ni sobre los alimentos que recibe.

Nombre y Apellido de la participante:

DNI:

Firma:

Nombre y Apellido del padre/ madre o tutor:

DNI:

Firma

Nombre y Apellido del Investigador Principal:

DNI:

Firma:

Nombre y Apellido de testigo:

DNI:

Firma: 


\section{Consulta de Datos de Establecimientos de la DGCyE}

\section{Dependencias}

Oficiales

Distrito: OLAVARRIA Tipo de Organización: ESCUELA PRIMARIA BASICA

\begin{tabular}{|c|c|}
\hline $\begin{array}{c}\text { Número de } \\
\text { Establecimiento }\end{array}$ & Nombre del Establecimiento \\
\hline 32 & MINISTRO WILDE \\
\hline 59 & HERMANAS CARO \\
\hline 17 & HELENA LARROQUE DE ROFFO \\
\hline 60 & ALMIRANTE GUILLERMO BROWN \\
\hline 24 & RUBEN DARIO \\
\hline 51 & PEDRO GOYENA \\
\hline 65 & REPUBLICA DEL PERU \\
\hline 2 & CAYRU MAIPU \\
\hline 52 & ANTARTIDA ARGENTINA \\
\hline 53 & CENTENARIO DE OLAVARRIA \\
\hline 56 & REPUBLICA DEL ECUADOR \\
\hline 57 & DAMASO ARCE \\
\hline 76 & HNAS. PINTO \\
\hline 1 & JUAN B. ALBERDI \\
\hline 4 & DOMINGO F. SARMIENTO \\
\hline 8 & GENERAL SAN MARTIN \\
\hline & \\
\hline
\end{tabular}




\begin{tabular}{|c|c|}
\hline 80 & CRUCERO GRAL. BELGRANO \\
\hline 11 & HIPOLITO YRIGOYEN \\
\hline 14 & REMEDIOS ESCALADA DE SAN MARTIN \\
\hline 22 & LANCEROS GRAL. PAZ \\
\hline 6 & CORONEL OLAVARRIA \\
\hline 7 & JUAN XXIII \\
\hline 10 & MARTIN MIGUEL DE GÜEMES \\
\hline 12 & MARIA CURIE \\
\hline 50 & ISLAS MALVINAS \\
\hline 64 & ROSARIO VERA PEÑALOZA \\
\hline 67 & DR. ALBERTO VALVERDE \\
\hline 69 & RICARDO GÜIRALDES \\
\hline 79 & ALFREDO FORTABAT \\
\hline 81 & JOSE M.ESTRADA \\
\hline
\end{tabular}

- Matrícula Total: 27056

Estatales: 21809

Privados: 5246

- Total de escuelas

Estatales: 68

Privadas: 11 


\section{Grupos etáreos}

\section{6 años}

Varones

2391

Mujeres 2207

Total 4599

7 años

Varones

2293

Mujeres 2034

Total 4328

8 años

Varones

2089

Mujeres

2482

Total 4572

9 años

Varones 2439

Mujeres 2079

Total 4518

10 años

Varones

2193

Mujeres 2108

Total 4301

\section{Gráficos y Tablas}

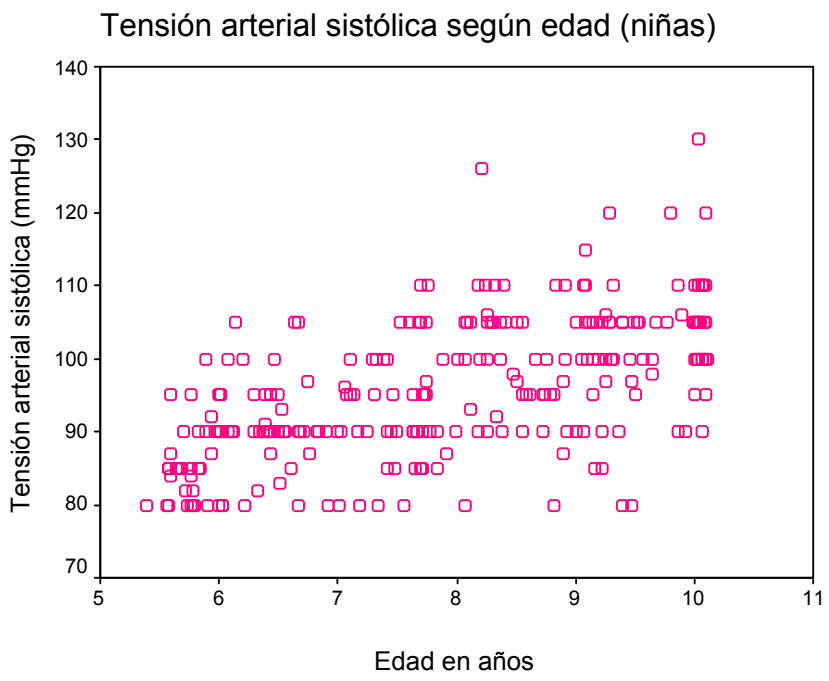




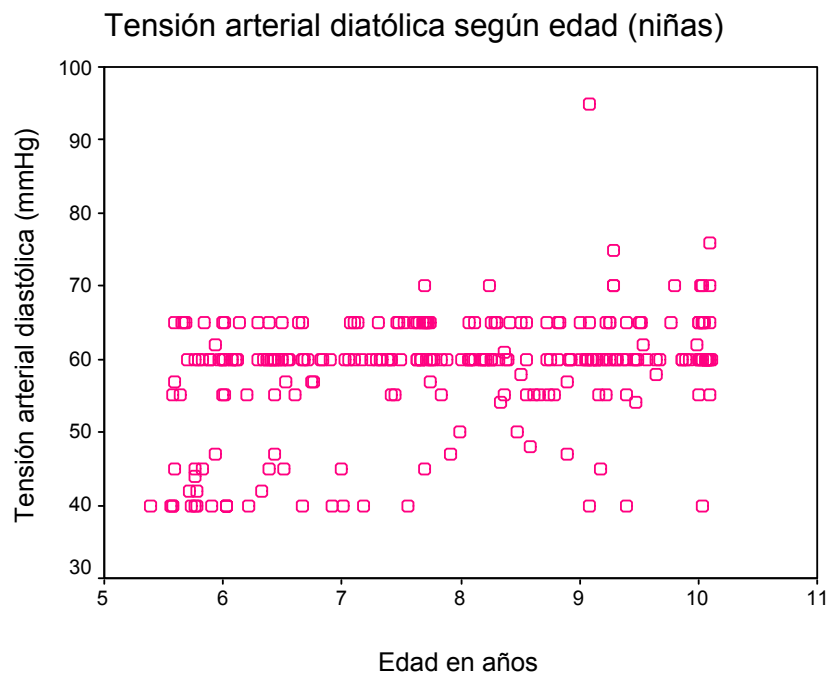

Tensión arterial sistólica según edad (niños)

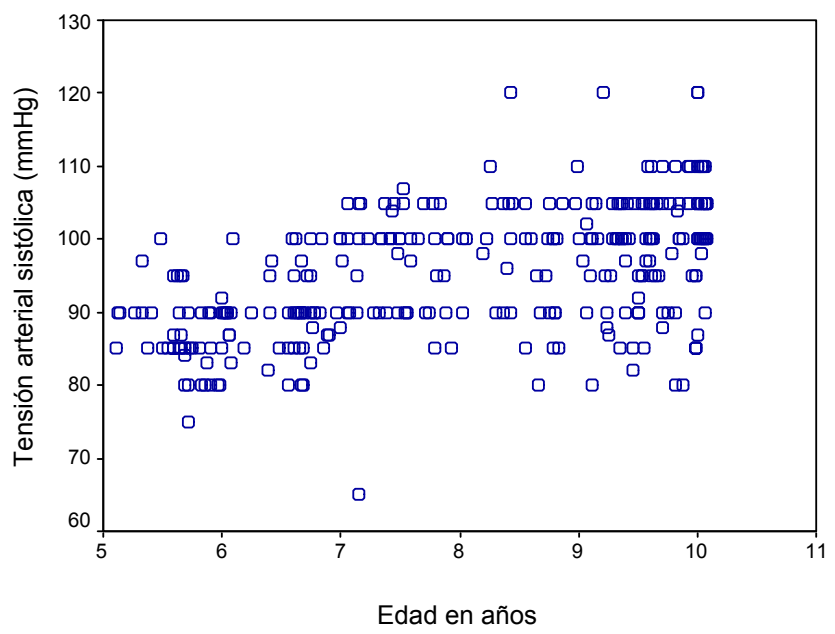

\section{Cintura según edad (niños)}

Report

CINTURA
\begin{tabular}{|l|l|r|r|}
\hline EDADA & Mean & N & Std. Deviation \\
\hline 5 & 55,5227 & 44 & 6,0865 \\
6 & 57,7551 & 49 & 6,0502 \\
7 & 60,2826 & 46 & 8,2615 \\
8 & 59,1026 & 39 & 6,0254 \\
9 & 64,7191 & 89 & 8,8420 \\
10 & 68,4286 & 28 & 10,0386 \\
Total & 61,1085 & 295 & 8,6847 \\
\hline
\end{tabular}

Cintura según edad (niñas) 


\section{Report}

CINTURA

\begin{tabular}{|l|l|r|r|}
\hline EDADA & Mean & N & Std. Deviation \\
\hline 5 & 55,7647 & 34 & 5,0755 \\
6 & 57,5918 & 49 & 6,9520 \\
7 & 61,2308 & 52 & 7,3207 \\
8 & 64,7619 & 42 & 9,2652 \\
9 & 62,1296 & 54 & 7,4582 \\
10 & 65,3214 & 28 & 7,0188 \\
Total & 61,0270 & 259 & 7,9706 \\
\hline
\end{tabular}


No gordos

Report

TAD
\begin{tabular}{|l|l|r|r|}
\hline EDADA & Mean & N & Std. Deviation \\
\hline 5 & 53,2903 & 31 & 8,3154 \\
6 & 57,5952 & 42 & 6,1765 \\
7 & 60,2368 & 38 & 3,6349 \\
8 & 57,8846 & 26 & 5,7781 \\
9 & 59,9692 & 65 & 7,9056 \\
10 & 61,8750 & 16 & 7,2744 \\
Total & 58,5000 & 218 & 7,1451 \\
\hline
\end{tabular}

Grupo 3

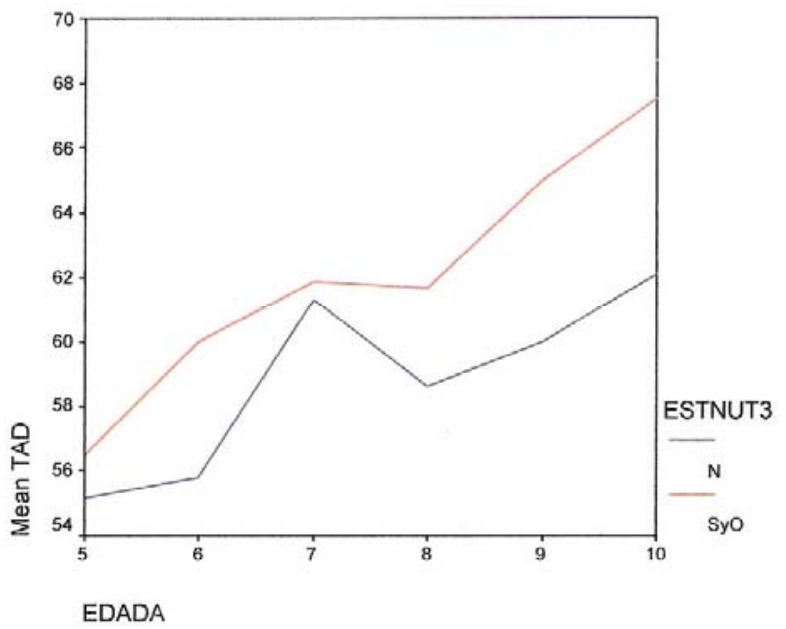

Gordos

Report

TAD

\begin{tabular}{|l|l|r|r|}
\hline EDADA & Mean & N & Std. Deviation \\
\hline 5 & 56,5000 & 8 & 5,2915 \\
6 & 60,0000 & 2 &, 0000 \\
7 & 61,8750 & 8 & 3,7201 \\
8 & 61,6667 & 9 & 6,1237 \\
9 & 65,0000 & 3 & 5,0000 \\
10 & 67,5000 & 6 & 4,1833 \\
Total & 61,7222 & 36 & 5,8241 \\
\hline
\end{tabular}




\section{Report}

TAD
\begin{tabular}{|l|l|r|r|}
\hline EDADA & Mean & N & Std. Deviation \\
\hline 5 & 51,8696 & 23 & 11,0959 \\
6 & 54,6000 & 35 & 7,9786 \\
7 & 60,0000 & 23 & 4,7673 \\
8 & 60,7500 & 32 & 3,8015 \\
9 & 59,9362 & 47 & 4,6129 \\
10 & 61,3684 & 19 & 4,5364 \\
Total & 58,1620 & 179 & 7,1737 \\
\hline
\end{tabular}

Grupo de escuela 1 y 3

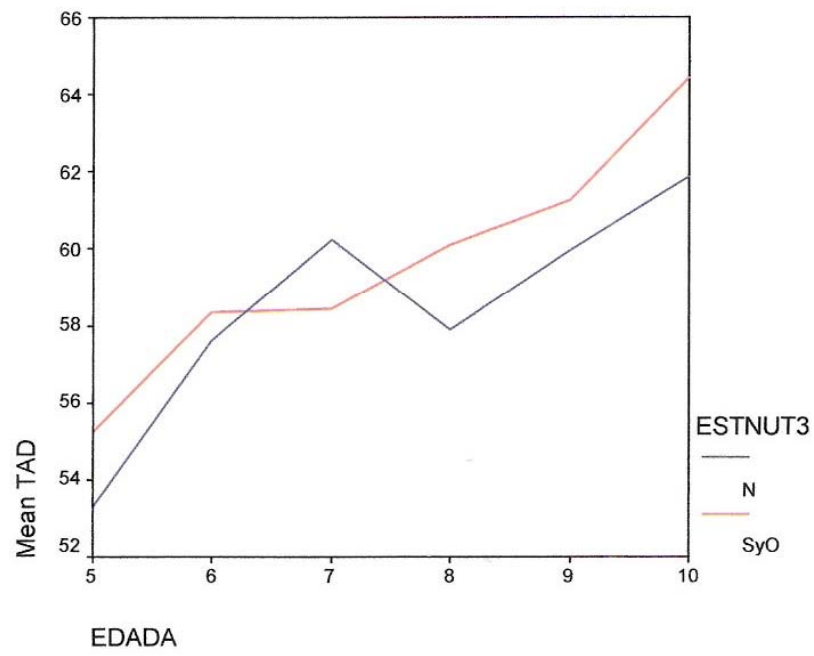

Gordos

Report

TAD
\begin{tabular}{|l|l|r|r|}
\hline EDADA & Mean & N & Std. Deviation \\
\hline 5 & 55,2667 & 15 & 6,9020 \\
6 & 58,3333 & 12 & 6,4291 \\
7 & 58,4231 & 26 & 7,2893 \\
8 & 60,1053 & 19 & 5,4762 \\
9 & 61,2941 & 17 & 7,1830 \\
10 & 64,4167 & 12 & 5,1779 \\
Total & 59,4554 & 101 & 6,9116 \\
\hline
\end{tabular}


Grupo 2 de escuela

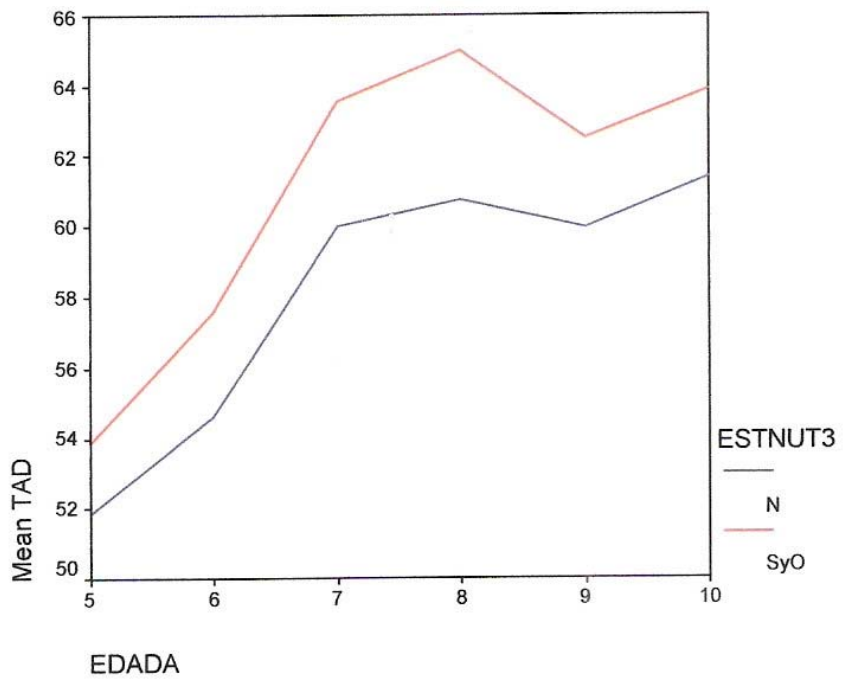

Gordos

Report

TAD

\begin{tabular}{|l|l|r|r|}
\hline EDADA & Mean & $\mathrm{N}$ & Std. Deviation \\
\hline 5 & 53,8889 & 9 & 9,9177 \\
6 & 57,6000 & 10 & 6,3631 \\
7 & 63,5455 & 11 & 9,2343 \\
8 & 65,0000 & 4 & 7,0711 \\
9 & 62,5000 & 12 & 6,9085 \\
10 & 63,8889 & 9 & 8,2074 \\
Total & 60,8182 & 55 & 8,6326 \\
\hline
\end{tabular}

No gordos

Report

TAD
\begin{tabular}{|l|l|r|r|}
\hline EDADA & Mean & N & Std. Deviation \\
\hline 5 & 51,8696 & 23 & 11,0959 \\
6 & 54,6000 & 35 & 7,9786 \\
7 & 60,0000 & 23 & 4,7673 \\
8 & 60,7500 & 32 & 3,8015 \\
9 & 59,9362 & 47 & 4,6129 \\
10 & 61,3684 & 19 & 4,5364 \\
Total & 58,1620 & 179 & 7,1737 \\
\hline
\end{tabular}




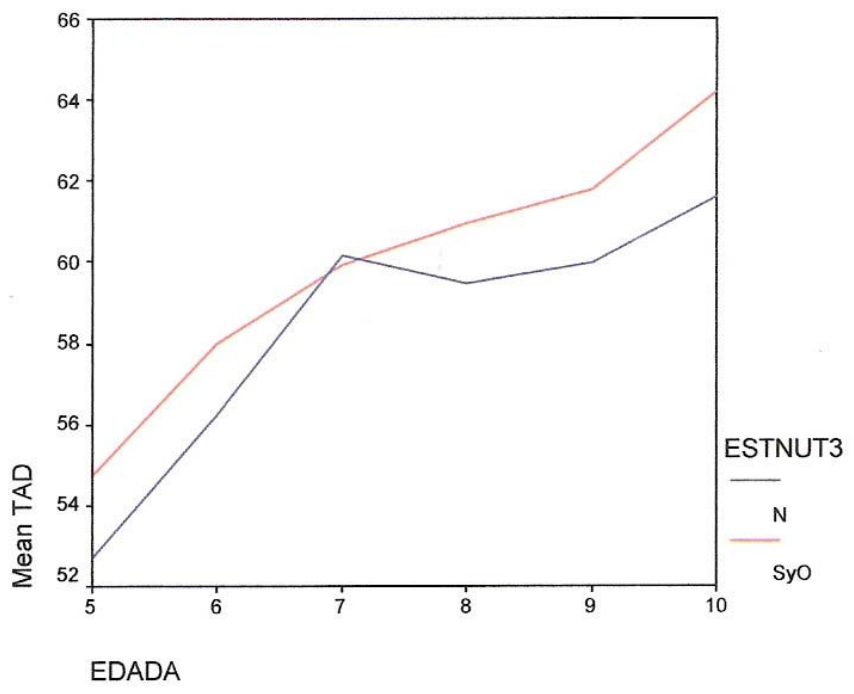

Gordos

Report

TAD
\begin{tabular}{|l|l|r|r|}
\hline EDADA & Mean & N & Std. Deviation \\
\hline 5 & 54,7500 & 24 & 7,9796 \\
6 & 58,0000 & 22 & 6,2564 \\
7 & 59,9459 & 37 & 8,1375 \\
8 & 60,9565 & 23 & 5,9121 \\
9 & 61,7931 & 29 & 6,9713 \\
10 & 64,1905 & 21 & 6,4623 \\
Total & 59,9359 & 156 & 7,5636 \\
\hline
\end{tabular}

No gordos

Report

TAD

\begin{tabular}{|l|l|r|r|}
\hline EDADA & Mean & N & Std. Deviation \\
\hline 5 & 52,6852 & 54 & 9,5262 \\
6 & 56,2338 & 77 & 7,1633 \\
7 & 60,1475 & 61 & 4,0613 \\
8 & 59,4655 & 58 & 4,9567 \\
9 & 59,9554 & 112 & 6,6973 \\
10 & 61,6000 & 35 & 5,8571 \\
Total & 58,3476 & 397 & 7,1510 \\
\hline
\end{tabular}


Correlations

\begin{tabular}{|ll|r|r|r|r|}
\hline & & \multicolumn{1}{|c|}{ ZPESO } & \multicolumn{1}{c|}{ IMC } & \multicolumn{1}{c|}{ TAD } & CINTURA \\
\hline ZPESO & Pearson Correlation & 1,000 &, $765^{* *}$ &, $250^{* *}$ &, $676^{* *}$ \\
& Sig. (2-tailed) &, &, 000 &, 000 &, 000 \\
& $\mathrm{~N}$ & 555 & 555 & 553 & 555 \\
\hline IMC & Pearson Correlation &, $765^{\star *}$ & 1,000 &, $247^{* *}$ &, $775^{*}$ \\
& Sig. (2-tailed) &, 000 &, &, 000 &, 000 \\
& $\mathrm{~N}$ & 555 & 555 & 553 & 555 \\
\hline TAD & Pearson Correlation &, $250^{* *}$ &, $247^{* *}$ & 1,000 &, $323^{* *}$ \\
& Sig. (2-tailed) &, 000 &, 000 &, &, 000 \\
& $\mathrm{~N}$ & 553 & 553 & 553 & 553 \\
\hline CINTURA & Pearson Correlation &, $676^{* *}$ &, $775^{* *}$ &, $323^{* *}$ & 1,000 \\
& Sig. (2-tailed) &, 000 &, 000 &, 000 &, \\
& $\mathrm{~N}$ & 555 & 555 & 553 & 555 \\
\hline
\end{tabular}

${ }^{* *}$. Correlation is significant at the 0.01 level (2-tailed).

Existe una correlación positiva aunque débil entre TAD y zpeso $(r=0.250, p=0.0$ $\mathrm{Y}$ entre TAD y IMC $(\mathrm{r}=0.247, \mathrm{p}=0.000)$

$\mathrm{Y}$ entre TAD y cintura $(\mathrm{r}=0.323, \mathrm{p}=0.000) \searrow$ 

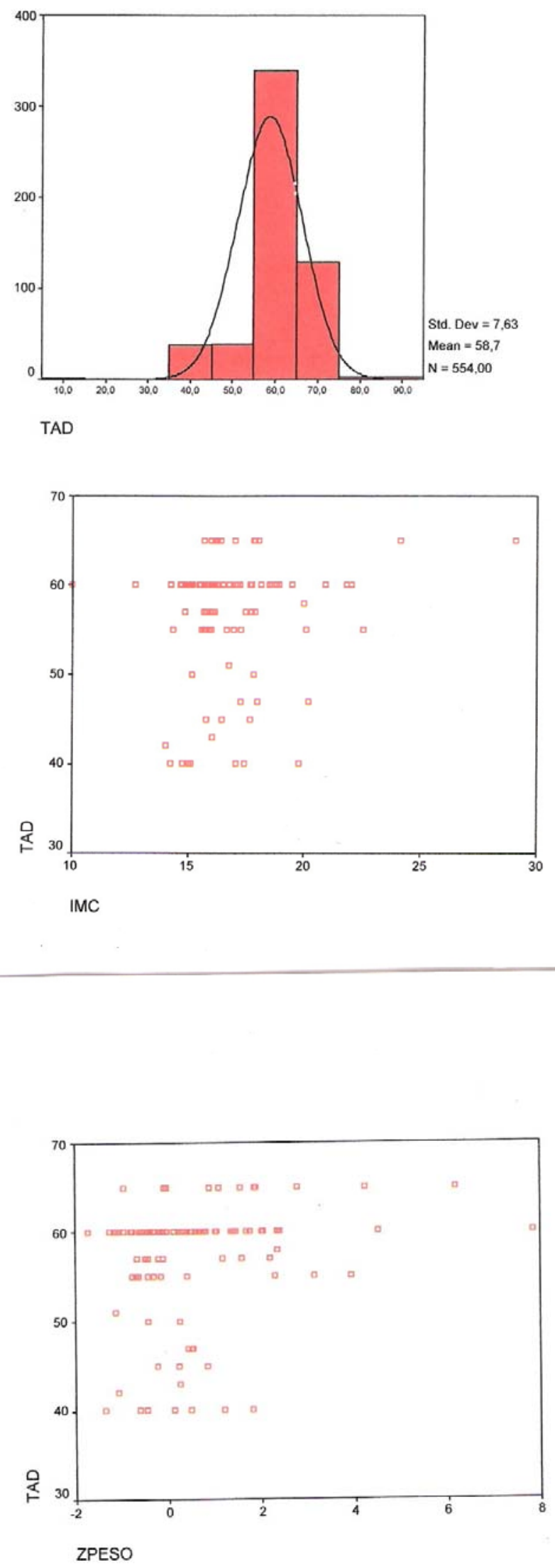


\begin{tabular}{|c|c|c|c|c|c|c|}
\hline & & & \multicolumn{3}{|c|}{ PESOBAJO } & \multirow[b]{2}{*}{ Total } \\
\hline & & & 1 & 2 & 3 & \\
\hline \multirow[t]{6}{*}{ CATESC } & 1 & Count & 1 & 3 & 190 & 194 \\
\hline & & $\%$ within CATESC &, $5 \%$ & $1,5 \%$ & $97,9 \%$ & $100,0 \%$ \\
\hline & 2 & Count & & 7 & 228 & 235 \\
\hline & & $\%$ within CATESC & & $3,0 \%$ & $97,0 \%$ & $100,0 \%$ \\
\hline & 3 & Count & 1 & 4 & 121 & 126 \\
\hline & & $\%$ within CATESC & $8 \%$ & $3,2 \%$ & $96,0 \%$ & $100,0 \%$ \\
\hline \multirow{2}{*}{\multicolumn{2}{|c|}{ Total }} & Count & 2 & 14 & 539 & 555 \\
\hline & & $\%$ within CATESC &, $4 \%$ & $2,5 \%$ & $97,1 \%$ & $100,0 \%$ \\
\hline
\end{tabular}

$P=0.592$

Crosstab

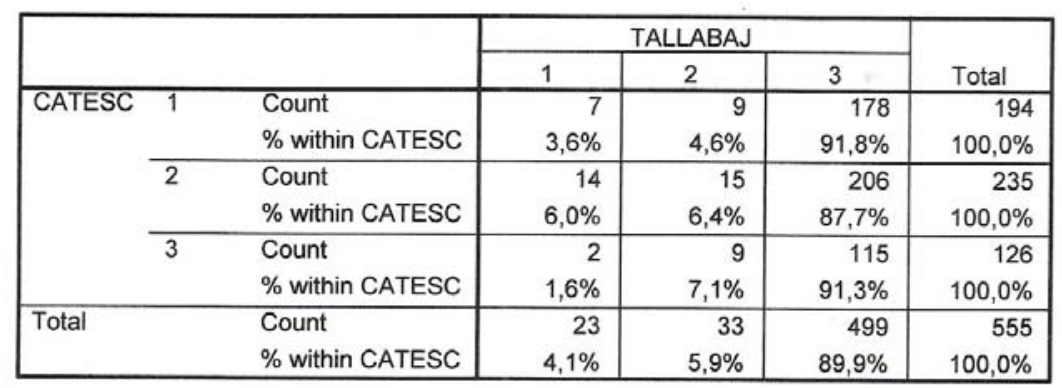

$P=0.272$

Descriptives

ZTALLA

\begin{tabular}{|c|c|c|c|c|c|c|c|c|}
\hline & \multirow[b]{2}{*}{$\mathrm{N}$} & \multirow[b]{2}{*}{ Mean } & \multirow[b]{2}{*}{ Std. Deviation } & \multirow[b]{2}{*}{ Std. Error } & \multicolumn{2}{|c|}{$\begin{array}{c}95 \% \text { Confidence Interval for } \\
\text { Mean }\end{array}$} & \multirow[b]{2}{*}{ Minimum } & \multirow[b]{2}{*}{ Maximum } \\
\hline & & & & & Lower Bound & Upper Bound & & \\
\hline 1 & 194 & .4564 & 1,3466 & $9,668 \mathrm{E}-02$ & .2657 & 6471 & $-3,12$ & 4,41 \\
\hline 2 & 234 & 1891 & 1,3385 & $8,750 \mathrm{E}-02$ & 1,667E-02 & 3614 & $-2,96$ & 4,53 \\
\hline 3 & 126 & ,4244 & 1,2523 & , 1116 & ,2036 & 6452 & $-2,53$ & 3,80 \\
\hline Total & 554 & .3362 & 1,3259 & $5,633 \mathrm{E}-02$ & 2255 & 4468 & $-3,12$ & 4,53 \\
\hline
\end{tabular}

$\mathrm{P}=0.081$ 


\section{Grupo 3}
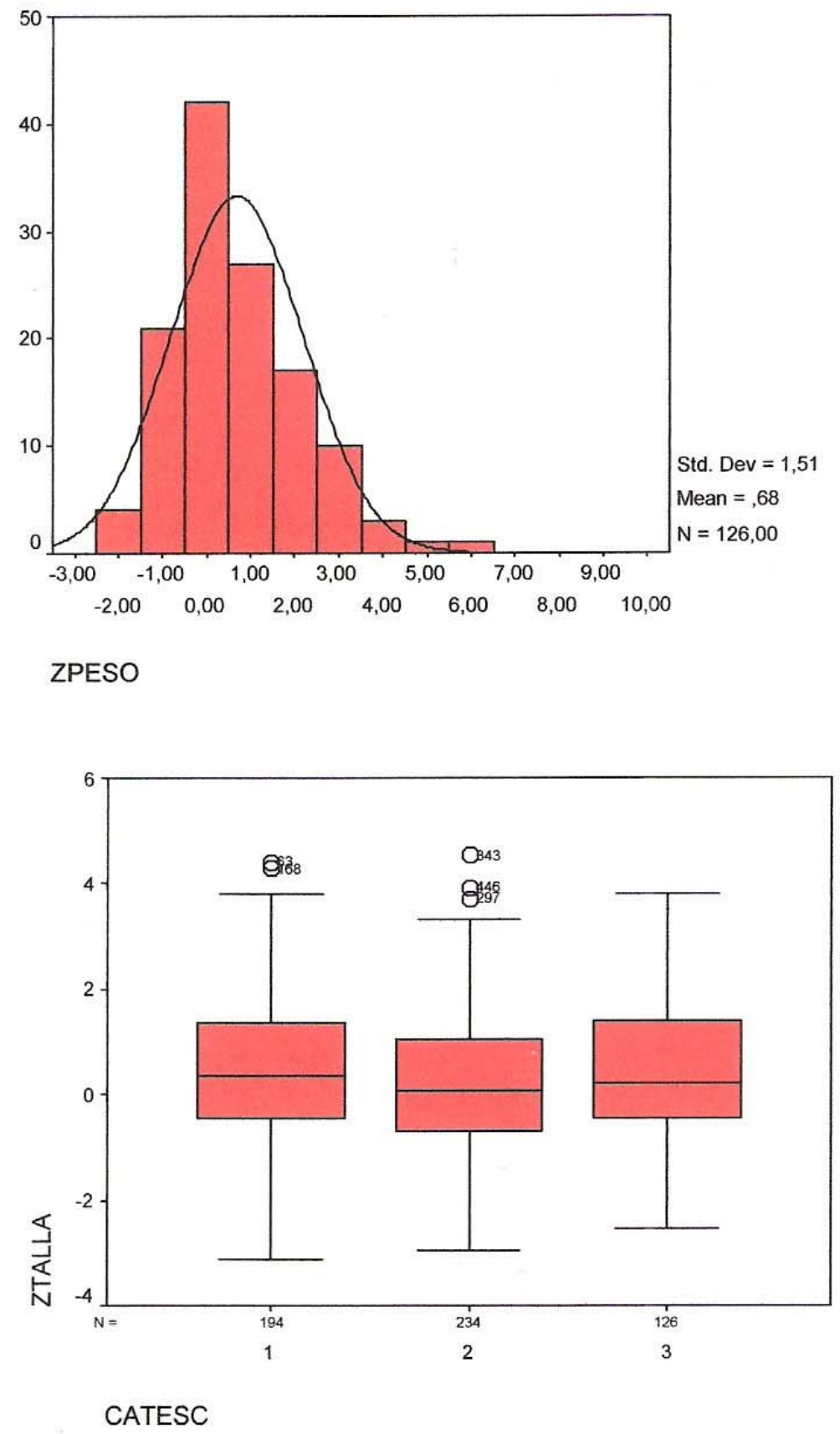
ESTNUI

\begin{tabular}{|ll|r|r|r|r|}
\hline & & & & \multicolumn{1}{c|}{$\begin{array}{c}\text { Cumulative } \\
\text { Percent }\end{array}$} \\
\hline Valid & D & 32 & 5,8 & 5,8 & 5,8 \\
& N & 367 & 66,1 & 66,1 & 71,9 \\
& O & 53 & 9,5 & 9,5 & 81,4 \\
& S & 103 & 18,6 & 18,6 & 100,0 \\
& Total & 555 & 100,0 & 100,0 & \\
\hline
\end{tabular}

CATESC * ESTNUT Crosstabulation

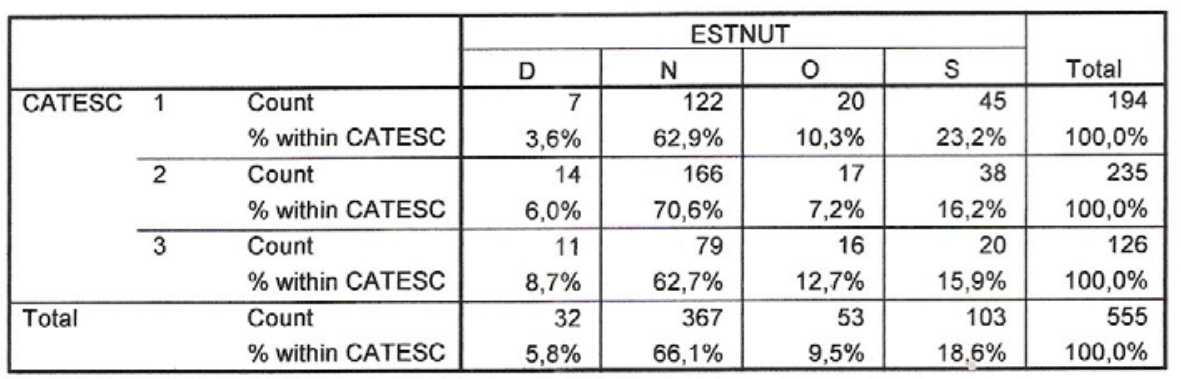

\section{$P=0.090$}

CATESC * ESTNUT2 Crosstabulation

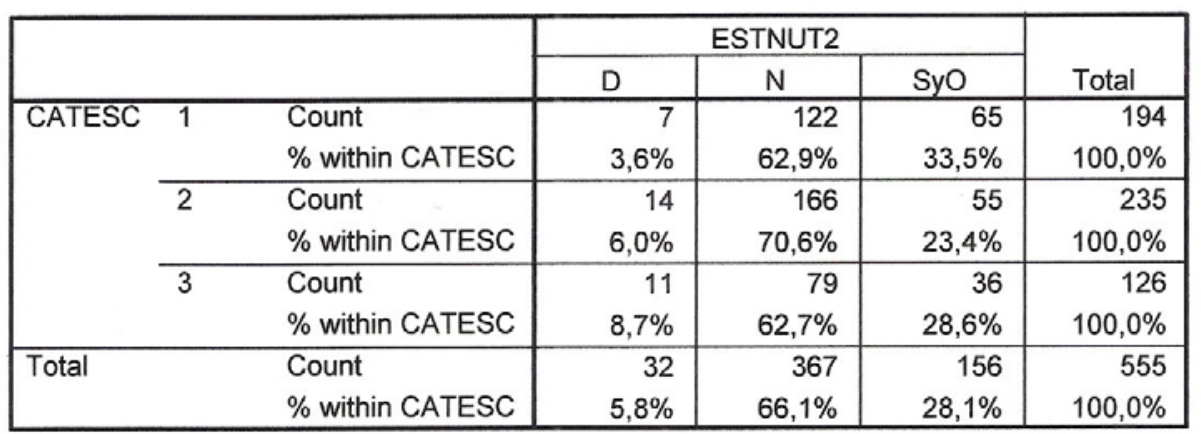

$P=0.071$ 


\section{Grupo 3}
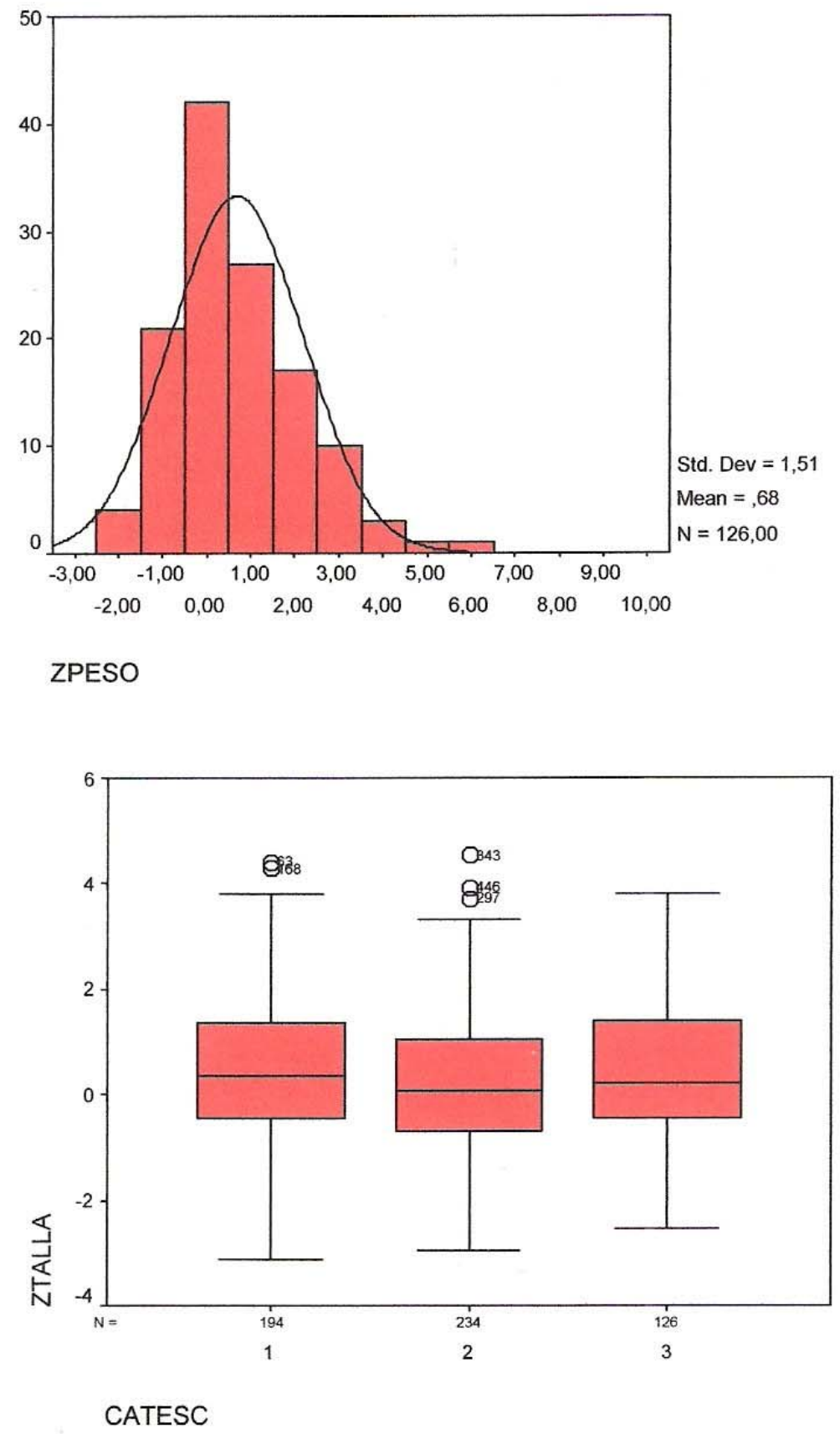


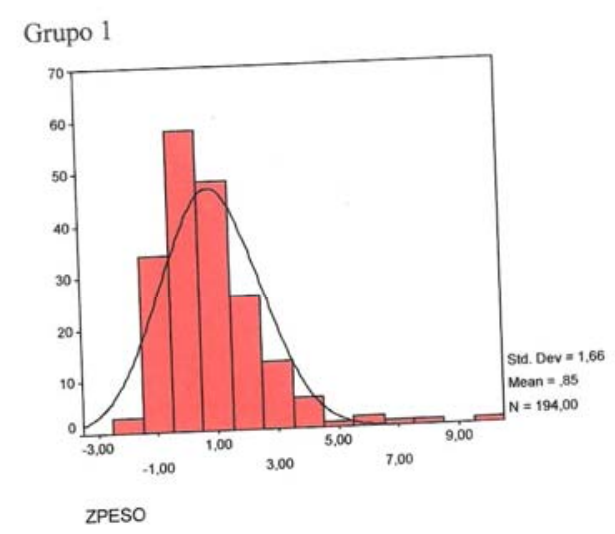

Grupo 2

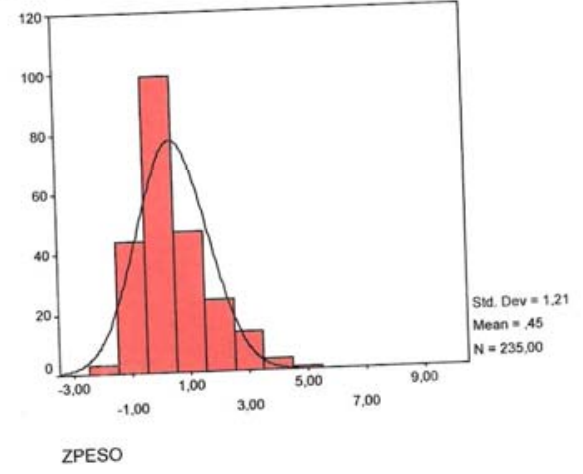




\section{Report}

TAD
\begin{tabular}{|l|l|r|r|}
\hline EDADA & Mean & N & Std. Deviation \\
\hline 5 & 55,1429 & 14 & 7,7147 \\
6 & 55,7857 & 14 & 7,4336 \\
7 & 61,3333 & 9 & 2,9155 \\
8 & 58,6250 & 16 & 5,3151 \\
9 & 60,0000 & 25 & 9,5743 \\
10 & 62,0833 & 12 & 8,1068 \\
Total & 58,7556 & 90 & 7,8215 \\
\hline
\end{tabular}




\section{Grupo 3}
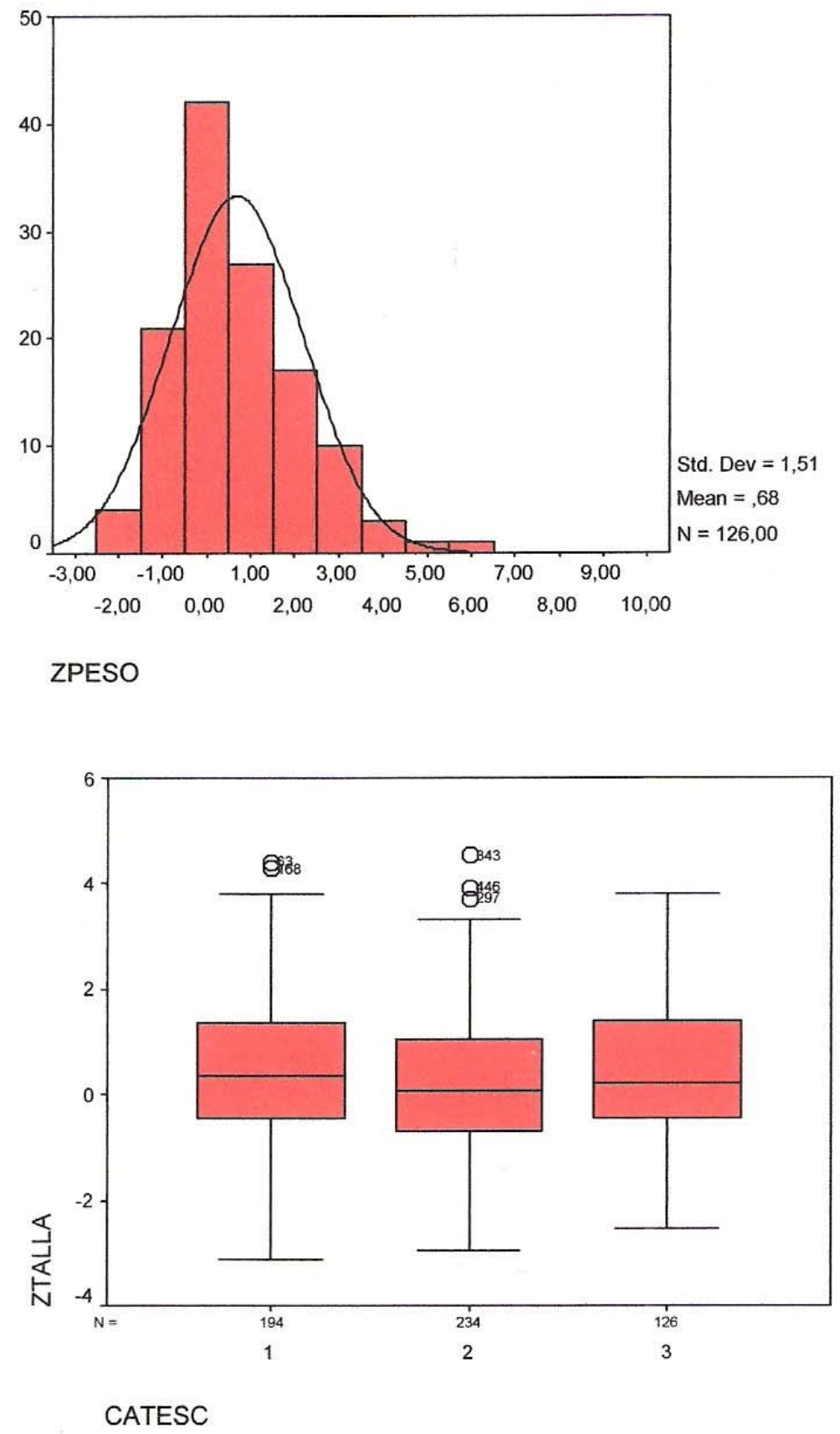

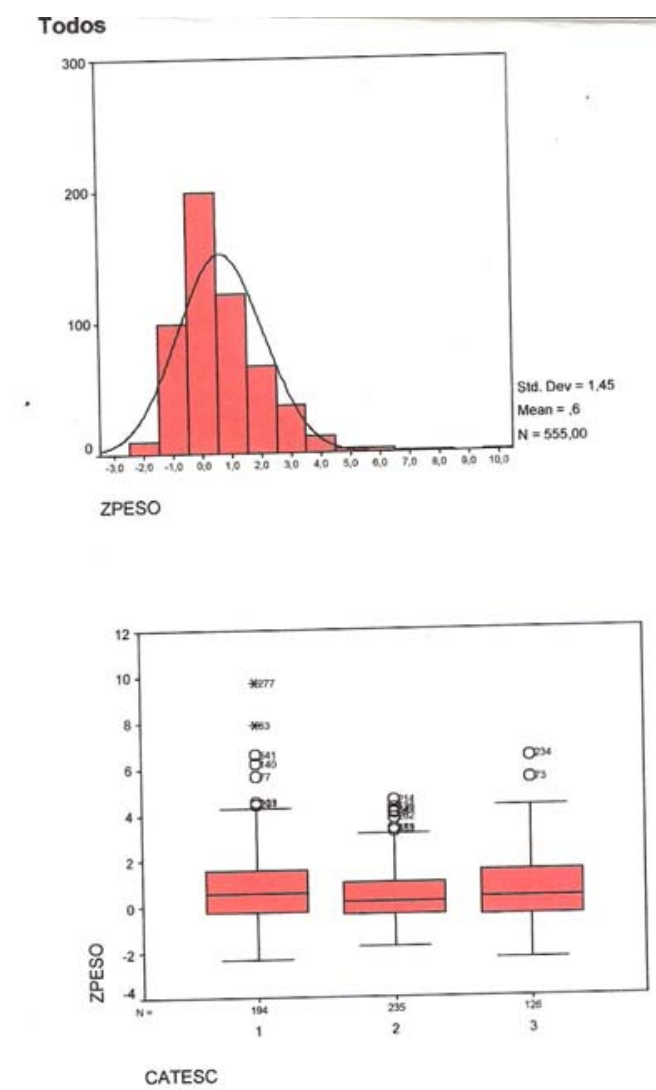

\begin{tabular}{|c|c|c|c|c|c|}
\hline \\
\hline & & Frequency & Percent & Valid Percent & $\begin{array}{c}\text { Cumulative } \\
\text { Percent }\end{array}$ \\
\hline \multirow[t]{4}{*}{ Valid } & bajo-2z & 2 & .4 & 4 & .4 \\
\hline & entre-2y-1.28 & 14 & 2.5 & 2,5 & 2.9 \\
\hline & sobre -1.28 & 539 & 97,1 & 97,1 & 100,0 \\
\hline & Total & 555 & 100,0 & 100,0 & \\
\hline
\end{tabular}

\begin{tabular}{|c|c|c|c|c|c|}
\hline & & Frequency & Percent & Valid Percent & $\begin{array}{c}\text { Cumulative } \\
\text { Percent }\end{array}$ \\
\hline \multirow[t]{4}{*}{ Valid } & bajo de $-2 z$ & 23 & 4,1 & 4,1 & 4,1 \\
\hline & entre $-2 y-1.28$ & 33 & 5,9 & 5,9 & 10,1 \\
\hline & arriba de -1.28 & 499 & 89,9 & 89,9 & 100,0 \\
\hline & Total & 555 & 100,0 & 100,0 & \\
\hline
\end{tabular}

